\title{
LA FILOSOFÍA DEL NO EN JOSÉ GAOS
}

CARLOS LLANO

FACULTAD DE FILOSOFIA

UNIVERSIDAD PANAMERICANA

La negación es uno de los temas más densos entre los abordados por José Gaos, pero es una de las claves para interpretar con acierto el núcleo de su pensamiento. ${ }^{1}$

Es posible que nadie como José Gaos haya teorizado sobre la negación, la nada y el no con tanta profundidad en este siglo, incluyendo a los filósofos existencialistas y al propio Jean-Paul Sartre, pese a su extenso estudio $E l$ ser y la nada. Las aproximaciones hechas por José Gaos a este recurrente tema de la filosofía son del todo originales. Alcanzan un nivel de radicalidad que por lo menos complementa los análisis de la fenomenología de la nada y de la negación considerados predominantes en la filosofía occidental del presente siglo.

Cuando Gaos inicia su estudio de la negación tiene conciencia de que, hasta ese momento, no se ha hecho un análisis fenomenológico completo y exhaustivo ( $F$ 289) a pesar de la importancia que ha revestido para la historia de la filosofía, "pero quizá nunca como en nuestros días, por las filosofías llamadas 'existencialismo'" (F 289).

El hecho de que su tema se exprese con el doble término de la negación o lo negativo, tiene ya importancia, pues se encuentra estrechamente relacionado con el punto de partida de su indagación: la presencia de los entes (signo por lo menos inequívoco de su existencia) así como la aparición, desaparición y reaparición que los acompañan. Ello pone a Gaos en

1 El tema de la negación ha sido expresamente abordado por José Gaos en sus dos últimas obras: De la filosofía (Universidad Nacional Autónoma de México, México, 1982) y su obra póstuma Del hombre (Universidad Nacional Autónoma de México, México, 1992). El tema de la negación lo ha desarrollado en las lecciones IX a XI de De la filosofía (pp. 289-324), que citaremos como $F$, y en las Lecciones XXV-XXVII de Del hombre (pp. 327-374), que citaremos como H. También en esta cuestión se cumple lo asentado por Fernando Salmerón (del Instituto de Investigaciones Filosoficas de la Universidad Nacional Autónoma de México, quien tuvo a su cargo la edición de las obras completas de Gaos) acerca de las relaciones de estas dos obras: lo que se encuentra implícito en De la filosofía se explicita en Del hombre, y en Del hombre se resume o alude a lo que ha estudiado especialmente en De la filosofia. 
contacto con los fenómenos de inexistencia anterior e inexistencia posterior, lo que lo hace concebir la existencia como algo finito - finito o delimitado precisamente entre la inexistencia anterior y la inexistencia posterior. Esto, a su vez, por la incomprensibilidad de tales relaciones, lo ha hecho concebir una existencia infinita. Como dirá en otros puntos de su obra ( $H$ 398), el hombre no es sólo el ser que piensa en la negación, sino también el que piensa en el infinito.

La incomprensibilidad de estos conceptos fuerza el entendimiento a la concepción de una existencia infinita (no fenoménica para Gaos, pero de importancia capital en la metafísica).

De modo que inexistencia y existencia infinitas son para nuestro autor las negaciones radicales y constituyen "la cuestión suprema de la razón humana, o sea, de la esencia del hombre, o sea, de la Antropología filosófica" ( $H$ 397), y un atisbo o presagio metafísico, del que ofrece múltiples señas dentro de sus desarrollos puramente fenomenológicos.

Estos fenómenos se relacionan con el doble término de la negación o lo negativo porque hay negaciones que no expresan algo negativo perteneciente al ser del que se niegan. Lotze, al distinguir también entre la negación y lo negativo, nos dice que existen negaciones de dos clases: la que niega la existencia de un objeto (hoy no llueve) o negación pura, y la que expresa una negación en estado positivo (aquel hombre está ciego).

Tal clase de negaciones, dice Lotze, tiene para la metafísica importancia decisiva, pues el espíritu finito sólo puede avanzar hacia lo infinito mediante la negación. Esto es, puesto que la infinitud no le es al hombre directamente accesible —no le es fenoménica, diría Gaos-, forma el concepto de ella afirmando el concepto de una perfección, pero negando al mismo tiempo todo límite con que aquella perfección se nos ofrece. ${ }^{2}$ En el fondo, habría aquí una negación de la negación (de ningún modo hegeliana), porque el límite no dice más que negación de una perfección ulterior posible más allá del límite mismo, y lo que se negaría sería precisamente el límite.

El modo de conocer descrito se llama en el lenguaje técnico escolástico vía de la negación o remoción, y más modernamente la llamada teología negativa.

Hay aquí también un leve contacto con lo que de legítimo se encuentra contenido en el "poder de lo negativo" (Macht des Negativen) que tanta importancia tuvo para Hegel, aunque en Gaos ese poder de lo negativo, subrayado por los existencialistas, tiene un peso muy mesurado.

José Gaos no es ajeno a la importancia de esta doble negación: "las expresiones 'inexistencia', 'infinitud' son negativas, estando compuestas con

2 Cfr. Tomás de Aquino, Summa theologiae, I, q. 13, a. 5: "Si los nombres de Dios y las criaturas se dicen unívocamente." 
el prefijo de 'sentido' negativo 'in-'. La expresión 'finitud' es positiva, pero el concepto notificado por ella, 'finitud', pudiera ser negativo" ( $F$ 289). Si bien nuestro autor se abstiene de toda conclusión metafísica, aunque la vislumbre, esta negación de algo que pudiera ser negativo, lo introduce en "las categorías de la razón negativas, en las que están, al parecer paradójicamente, lo más alto y lo más profundo, a la una, de la razón" ( F 289).

La cautela del lenguaje deja traslucir que la puerta abierta de estas categorías negativas, ejemplificadas con el prefijo privativo in-, nos introduciría en el mundo transfenoménico de lo inconmensurable, intemporal, inmortal... en el ámbito, en suma, de la metafísica.

\section{Las categorías negativas de la expresión verbal}

El existencialismo inicia sus análisis sobre la nada, el no-ser, la negación, lo negativo..., a partir de vivencias muy heterogéneas, de diverso valor.

Anticipándose a todos, Baudelaire (y después Sartre y Octavio Paz) relaciona la nada con el aburrimiento. Kierkegaard parte de la soledad del sujeto; Jaspers, dèl fracaso; Heidegger, del ser para la muerte; para Marcel la vivencia de la nada surge y se resuelve de y por la disponibilidad. En Jean-Paul Sartre encontramos una variedad disímbola: la náusea al descubrir que detrás de las cosas no hay nada; la decepción, cuando la realidad no corresponde a nuestras expectativas; la ausencia, fenómeno que Octavio Paz modulará como ausencia del ser amado; la angustia de la libertad que se capta a sí misma como infundamentada...

Parecería que José Gaos, profundo conocedor del existencialismo, heredero de Ortega y confesado vitalista, tomaría como punto de partida de su fenomenología de la negación, sentimientos o vivencias semejantes.

En cambio, parte de la negación como se manifiesta en la expresión verbal, no en las vivencias existenciales. Pensamos que lo hace así porque la palabra es paradigmáticamente fenoménica. Si por fenómeno entendemos lo que se manifiesta, podría decirse, aunque Gaos no lo diga, que la palabra es constitutivamente manifestativa del yo que se manifiesta, del objeto manifestado y de sí misma. Ante las elucubraciones cabalísticas de Heidegger, habremos de darle a Gaos la razón por el acierto de su punto de partida.

Gaos busca la negación radical, aquella que fundamenta todas las demás. El inventario - exhaustivo incluso para el lector- que lleva a cabo en De la filosofía tiene por finalidad ir relegando formas secundarias de negación. $\mathrm{Y}$ esto lo hace profundamente, sin dar nada por supuesto. Tal ocurre con las dos primeras expresiones verbales ante las que decide: "esta hoja no es amarilla" o bien "niego que esta hoja sea amarilla" ( F 293). Todo parecería indicar que la negación manifestada en el segundo juicio alcanza un mayor 
nivel de radicalidad, ya que el acto de negar se encuentra explícito (niego que), lo que no acaece en el primero (esta hoja no).

José Gaos opta en sentido contrario, porque la negación del primer juicio se refiere directamente al objeto negado (el amarillo de la hoja), mientras que en el segundo no se refiere a un objeto sino a una proposición: la de que "esta hoja es amarilla". La negación del objeto es una negación directa; la de la proposición es una negación indirecta del objeto, porque lo negado no es el objeto, sino la proposición.

Gaos no tiene ahora en cuenta el carácter reflexivo -y por tanto indirecto- del conocimiento humano, especialmente en el juicio. Todo juicio, negativo o afirmativo, es, de alguna manera, indirecto. Al decir directamente "esta hoja es amarilla", estoy en realidad diciendo: "afirmo o juzgo que esta hoja es amarilla", expresión de la que la primera sería sólo elíptica. Todo juicio sería por tanto indirecto porque no sólo sería dictivo de un ti (el amarillo que se niega de la hoja), sino expresivo de una diánoia (el hecho noético de negar el amarillo de la hoja). Según Tomás de Aquino, esta presencia del sujeto judicante en todo juicio es lo que hace posible formalmente la verdad de éste, en cuanto que exige una correspondencia o adecuación entre lo que juzga el sujeto y el objeto juzgado. ${ }^{3}$

Esta omisión de quien, por parte, otorga mucha importancia al sujeto del conocimiento no acarrea consecuencias, porque el sujeto reaparece por lo menos en dos ocasiones que ahora sólo mencionamos: en la estructura del fenómeno de la presencia y en la etiología de la negación.

Para Gaos toda expresión verbal no sólo designa el objeto expresado o notifica el concepto que se expresa, sino que, simultáneamente, significa los sentimientos del sujeto que expresa.

Las expresiones interrogativas, exclamativas e imperativas tienen una mayor carga de significación referida al sujeto que interroga, exclama o manda, en tanto que en las expresiones meramente enunciativas, el ingrediente de designación del objeto tiene mucho mayor peso, aunque nunca estará ausente la dimensión significativa del sujeto (su ecuanimidad u objetividad).

Pues bien: "la negación ocupa [...] un singular puesto intermedio" (H 328), entre la designación de las proposiciones enunciativas y la significación de las interrogativas, exclamativas e imperativas. Se verán después, sin embargo, las razones que Gaos tiene para tal aserto.

Excusémonos del inventario y clasificación de las negaciones, que con prolijidad paciente se lleva a cabo tanto en De la filosofía ( $F 294$ y ss.) como en Del hombre ( $H 328$ y ss.), concluyendo que "las expresiones más propiamente negativas son aquéllas con las que se niega directa y simplemente"

3 Tomás de Aquino, Quaestio de veritate, q. 1, a. 3: "Si la verdad se da sólo en el juicio." 
(F 294), sobre lo que acabamos de hacer marginales observaciones, y de ellas las más importantes son las negaciones totales, o sea, las expresiones: no, in-, ninguno y nada. Es importante retener que para Gaos el prefijo "in"-, es sinónimo de "no". Por otra parte, ninguno y nada son para Gaos casos de "no". De manera que "no" debe considerarse como "la expresión negativa por excelencia, literalmente arquetípica, en el doble sentido de primitiva y principal" (F 294).

Gaos pone cuidado en mostrarnos que la expresión negativa por excelencia no, tiene un carácter plenario, ya que cualquier expresión es susceptible de ser negada con el término no. Así, el no del sustantivo (y anexos), como el no hombre de Unamuno: "un hombre que no es de aquí ni de allí, ni de esta época ni de la otra, que no tiene sexo ni patria, una idea, en fin. Es decir, un no hombre" (F 295). El no del adjetivo: lo no blanco (Aristóteles) (ibid.); del pronombre: no yo (Fichte) (ibid.); del adverbio: no hoy, no así, no más (ibid.); del verbo o actividad: no ama. La única negación no castellana inventariada por Gaos es la latina nusquam.

$\mathrm{El}$ "no" puede negar "todo individuo o concepto, o existente, distributiva o singular y colectiva o pluralmente tomado". Por ello, siendo existente un trascendental positivo, “'no' es él mismo el trascendental negativo" ( $F$ 310 311). El enfrentamiento de Gaos con los existencialismos en boga reside precisamente en la decisiva cuestión acerca de si ese trascendental tiene su objeto en la nada, o es inobjetivable. Asunto que debe posponerse ahora.

\section{Fenomenología del no relativo}

Analizadas todas las posibles negaciones de nuestro lenguaje castellano, Gaos nos dice que es "innegable" que todas las formas del no que se investigaron antes pueden reducirse a proposiciones elípticas en las que se encuentra implícito el "es" como cópula. Vale decir, es un no que alude a la relación entre un sujeto y su predicado correspondiente. Por ejemplo, el no-hombre del que hablaba Unamuno sería una forma elíptica de este tipo: esa idea abstracta de hombre es un no-hombre. Aparece así el no "que puede llamarse 'relativo' por negar las relaciones notificadas por el verbo 'ser' en su construcción copulativa" ( $F$ 295). Más precisamente, se le denomina no relativo elíptico ( $F$ 296). Bien se ve que el no relativo no se opone al no absoluto sino más bien al no activo, es decir al “'no', que puede llamarse 'activo', por negar [no ya las relaciones sino] las actividades designadas por los verbos en sus formas personales..." ( $F$ 297): yo no amo, él no quiere, etcétera.

Gaos tropieza aquí con la sinonimia del ser, el cual tiene al menos dos sentidos principales: el ser como cópula y el ser como existencia, lo que ya fue advertido por Aristóteles en su Metafísica (VI, 2, 1026b 2) cuando 
nos indica que el ser se dice de muchas maneras ( $\pi 0 \lambda \lambda \alpha \chi \tilde{\omega} \varsigma \lambda \hat{\epsilon} \gamma \epsilon \tau \alpha \iota)$ y, de entre ellas, destacan fundamentalmente las dos que provocan el tropiezo de Gaos, al habérselas con la fenomenología del no: el ô $\nu \dot{\omega} \varsigma \alpha \dot{\alpha} \lambda \theta \dot{\epsilon} \varsigma$, el ser como verdadero, que equivaldría al ser como cópula en Gaos (la proposición será verdadera si los extremos asociados o disociados mediante la cópula es o no es se encuentran asociados o disociados en la realidad de las cosas), y el $\partial ̀ \nu \kappa v \rho i \omega \nu$ o ser propio de cada cosa, que sería el acto por el que cada cosa se erige en existente (Metafísica, VI, 4, 1027b 30).

Gaos resuelve el problema de la siguiente manera: llamará negación existencial a aquella en la que lo que se niega es el verbo "ser" como expresivo de existencia; negación copulativa cuando el "ser" se toma en cuanto relación de sujeto y predicado, relación que se niega en el "no es", y negación verbial cuando lo que se niega son las actividades que ejerce el sujeto, designadas por los verbos ( $H 330) .^{4}$

Pese a ello, hay un desacuerdo - y no es para menos- entre el ser copulativo y el ser existencial, igualmente determinados por el "no" ( $F$ 311). El ser copulativo y el ser existencial plantean no ya una homonimia, sino una ambigüedad: "más aún, [...] un equívoco múltiple" (F 312). Pero para Gaos, tanto el análisis de la negación del ser copulativo como el del ser existencial desembocarán en el mismo punto.

En De la filosofía (F 294 y ss.) analizará extensamente la negación copulativa ("no ser" como una negación en la que la negación existencial quedaría englobada dentro de ella) mientras que en Del hombre ( $H 331$ y ss.) lo hará con la negación existencial, considerándose entonces que la negación copulativa es modalizadora de la negación existencial. Por lo que toca a la negación verbial (la que niega las actividades expresadas por un verbo: no ama), se asimilará en De la filosofía a la negación copulativa, siendo la actividad un atributo más del sujeto de la proposición; mientras que en Del hombre se encontrará muy próxima a la negación existencial, al punto de presentarse la existencia como una actividad del sujeto existente, y la actividad del verbo como una modulación del ejercicio de esa existencia.

En De la filosofía lleva a cabo una investigación fenomenológica del "no" relativo (de la negación copulativa). Maneja Gaos dos pares de categorías:

4 Como acabamos de ver, en De la filosofía Gaos llama a la negación de actividades de un sujeto, "no" activo, por oposición al "no" relativo que niega no actividades sino relaciones (ser como cópula) ( $F$ 297). En cambio, en Del hombre aquel tipo de negaciones (el "no" activo) recibe el nombre de negación verbial. Nuestro filósofo se ve aquí obligado a arbitrar una nueva terminología. De forma análoga a como aquello que va adjunto al verbo se llama adverbio, denomina verbial a la negación de una actividad expresada por un verbo. Se ve forzado a hacerlo así porque, en caso de llamarla negación verbal, podría ésta confundirse con la negación verbal (oral o escrita) en oposición a la negación práctica, a la que se referirá en otros momentos ( $F 318$ y ss.). 
a) los juicios pueden hallarse en posición directa o en posición refleja; b) las expresiones pueden denotar o connotar objetos. Con paciencia, Gaos analiza el estatus del "no" relativo respecto de estos dos pares de categorías verbales.

"Esta hoja es amarilla" denota a esta hoja en posición directa y connota el carácter modal del amarillo de la hoja, en posición también directa. "Es", por su lado, denota en posición directa la relación que enlaza el objeto denotado en posición directa, hoja, con el atributo con ella connotado: amarilla.

Si dijera: "el juicio 'esta hoja es amarilla' es una proposición afirmativa", en tal caso esta hoja es amarilla denotaría en posición refleja la proposición dicha y cada uno de sus términos.

La proposición "esta hoja es amarilla" se ha convertido, al considerarla en posición refleja, en el objeto de mi conocimiento, no siéndolo ya de modo directo el amarillo de esta hoja ni esta hoja amarilla.

Como puede observarse, las expresiones o términos en posición directa y en posición refleja guardan cierta analogía con lo que Frege llamó predicados de primer nivel (el perro es un animal) y predicados de segundo nivel (animal es un predicado genérico de perro). $\mathrm{Y}$ son análogas también a las primae intentiones y secundae intentiones escolásticas: las primeras intenciones son conceptos que denotan directamente los objetos a que corresponden: perro, y lo que de animal tenga el perro; en cambio, las segundas intenciones expresan la categoría o lugar lógico que corresponde a los conceptos mencionados: ser sujeto de la proposición en el caso del perro; o el carácter de predicado y género en el caso de animal.

El reconocimiento que hace Gaos de las proposiciones en posición refleja (o relaciones de segundo nivel, en terminología de Frege), en cuanto diferentes de las proposiciones en posición directa que expresan relaciones reales es condición necesaria del realismo metafísico. Lo cual no quiere decir que Gaos se abandere bajo una metafísica realista; quiere decir sólo que, al admitir la especificidad de las relaciones reflejas, o de las proposiciones en posición refleja, se margina del inmanentismo de la representación, en el que rige el lema spinoziano según el cual el orden de las ideas es idéntico al orden de las cosas.

En la proposición, pues, "esta hoja es amarilla", en la que se denota en posición directa a esta hoja y se connota, también en posición directa, el amarillo de ella, puede hacerse una mutación, sustantivando el adjetivo amarillo, de manera que el objeto de este término se transforme en denotable y no ya sólo connotable o connotante. Esta mutación se hará diciendo "el amarillo que es de esta hoja", o "este amarillo de la hoja". "Un concepto connotante [...] objetiva, en posición directa, un objeto individual modal, denotable sustantivándolo y objetivándolo en posición directa" ( F 305). 
Pero la transformación hecha, por la que un término connotante o connotable (por expresar un modo del objeto) pasa a ser denotante al sustantivarse ("el amarillo que es de esta hoja"), no puede hacerse con todos los términos de la misma proposición. Gaos toma como ejemplo de tal imposibilidad el adjetivo demostrativo esta (de la hoja) o este (del amarillo), término que tiene en su filosofía particular importancia vital y noética. ${ }^{5}$

El término este no tiene capacidad de denotar ningún objeto en posición directa, sino sólo connotar modalmente al amarillo este de la hoja o a la hoja esta que es amarilla. Es un término que sólo tiene, en posición directa, la posibilidad de connotar, no de denotar ningún objeto. Efectivamente, este connota una modalidad del amarillo o, en su caso, de la hoja: esta modalidad es la proximidad de lo connotado (amarillo $\mathrm{u}$ hoja) respecto del sujeto que enuncia la proposición "este amarillo de la hoja" o "esta hoja es amarilla". "Este" indica que la hoja o el amarillo están situacionalmente próximos al sujeto del que los pronuncia, e individualizados por él.

El este de la proposición carece de objeto propio denotable en posición directa, es decir, él mismo no es susceptible de ser denotado en esa posición. Sin embargo, este es denotable en posición refleja cuando se hace, en esta posición, objeto de nuestro pensamiento. Así ocurre, por ejemplo, cuando decimos que "este 'este' se refiere al amarillo de la hoja". Aquí "este" ha sido objetivado en posición refleja y se constituye, de tal manera, en objeto de denotación, aunque en posición directa no denote nada sino sólo connote al amarillo o a la hoja. Lo mismo acontece cuando, poniendo otra vez "este" en posición refleja, decimos, por ejemplo, que "este 'este' es adjetivo demostrativo y no pronombre". (Tendríamos aquí un caso típico del ente de razón o intentio secunda, porque la distinción en él entre adjetivo demostrativo o pronombre demostrativo no se refiere a objetos reales denotados, sino sólo a lugares gramaticales o lógicos únicamente susceptibles de objetivación en posición refleja.) Los intentos para hacer que "este" sea denotable y/o denotante en posición directa, como los que pacientemente hace Gaos en De la filosofía, resultarán todos fallidos.

Advertimos marginalmente que Gaos hubiera contado con la posibilidad, ofrecida por la historia de la filosofía, de sustantivar el adjetivo "este", como antes lo hizo con el adjetivo "amarillo", para que, dentro de la misma posición directa, pasase a denotar un objeto y no sólo connotarlo. Tal es la operación hecha por Duns Scoto con su concepto de haecceitas (traducido bárbaramente al castellano como esteidad). La haecceitas es para Scoto la forma sustantivada del modo sustancial por el que la sustancia es ésta y no otra. Admitida una sustantivación de tal índole, podríamos transformar

5 Cfr. Carlos Llano, "El conocimiento del singular", Diánoia, no. XXXVI, México, 1990, pp. 17 y ss. 
la expresión en posición directa "esta hoja es amarilla" por "la haecceitas que hay en la hoja amarilla". No es necesario remontarse para ello a la alta Edad Media. Su coetáneo y colega Xavier Zubiri ha sustantivado la esencia de una realidad, que otorga el ser tal de ella, mediante el término talidad. ${ }^{6}$

Pero en Gaos el carácter singular indicado por el "este" o el "esta" no es una cualidad objetiva y absoluta del objeto, que resultara ser éste y no aquél, por notas individuantes suyas, sino por la relación que guarda con el sujeto psicológico de quien recibe la dicha denominación de "este" o "esta". Lo que hace que un objeto sea "este" no es para Gaos una nota objetiva, sino una relación situacional del objeto respecto del sujeto. ${ }^{7}$

\section{Indenotabilidad del "no"}

Consideremos ahora la proposición, negativa de la anterior, "esta hoja no es amarilla". Preparados ya por el manejo de esos dos binomios categoriales (posición directa o refleja en el caso de las proposiciones o juicios y denotación o connotación en las expresiones o términos) a propósito del demostrativo "este", hagamos un resumen del ejercicio que José Gaos practica con el término "no es" de esta última proposición - "esta hoja no es amarilla"- o el término "no ser", que es la sustantivación del "no es", o el mero "no" considerado elípticamente, incluido también en esa última proposición ( $F 304$ ss.). No podemos dejar de percatarnos de que el no de la proposición "esta hoja no es amarilla", en posición directa es connotante de la relación o cópula entre hoja y amarilla, modalizándola de "no". También nos percatamos de que el "no" sólo puede ser denotado en posición refleja, objetivándolo como concepto "no". Pero resulta imposible que "no" denote objeto alguno en posición directa. En este punto José Gaos es reiterativo, convincente y claro. "No" puede ser denotado, como cualquier otro concepto, en posición refleja (expresando una relación refleja irreal, diría Millán Puelles), pero fracasarán todos los esfuerzos para encontrar un objeto que en posición directa sea denotado por el término, concepto o expresión "no".

Lo denotado en posición directa en el juicio "esta hoja no es amarilla" es la hoja, la cual es connotada de "amarilla" y de "no" en la misma posición directa; pero el "no" "es denotable él mismo [sólo] sustantivándolo y objetivándolo en posición refleja" ( $F$ 308), nunca en posición directa.

Este punto constituye el clímax del análisis fenomenológico prometido y realizado por el pensador hispano-mexicano: "serían los conceptos negativos los únicos cuya connotación no sería denotable" ( F 309). Para nosotros

${ }^{6}$ Cfr. Xavier Zubiri, Sobre la esencia, Sociedad de Estudios y Publicaciones, Madrid, 1962, pp. 357 y ss.

7 Cfr. Carlos Llano, op. cit. 
el "no", como trascendental negativo, sería además trascendental por poder connotar negativamente en posición directa cualquier objeto, concepto o término, de cualquier tipo o clase, y además por no poder denotar en posición directa ningún objeto, concepto o término, de cualquier tipo o clase, que sería otra manera de considerar el "no" como trascendental negativo, complementaria de la anterior. ${ }^{8}$ Esta conclusión se traduce sobriamente así: la negación máxima, el "no" carece de objeto alguno. Con esto, Gaos se coloca frente a la copiosa tradición filosófica que, de alguna manera, trata de encontrar un objeto para la nada, o trata de hacer de la nada un objeto, pero no un objeto en posición refleja - esto es, un mero concepto-, lo que sería enteramente legítimo, sino un objeto con visos - cabalísticosde posición directa. Para explicar esta última conclusión (que es nuestra, no de Gaos), debemos proseguir, en su momento, lo que él mismo llamará fenomenología de la nada.

Antes, sin embargo, hemos de hacernos esta pregunta: si "los conceptos negativos [son] los únicos cuya connotación no sería denotable" ( $F$ 309) ¿no podría decirse exactamente lo mismo de conceptos como el "este" antes estudiado? La pregunta es razonable porque tampoco de "este" podemos mostrar un objeto que le corresponda directamente, además o fuera del que ya en la posición directa está connotando (amarillo u hoja). Parece, pues, que el concepto más determinante, afirmativo, posicionante e individualizado ("este") y el concepto más trascendentalmente negativo ("no") guardan, respecto a la denotación directa de sus objetos, una misma condición.

Gaos contesta que debe distinguirse "entre un concepto como 'este' y un concepto como 'no'. Una relación [como la establecida por 'este'], aunque no sea más que un concepto, es un concepto lleno, por decirlo así, que coopera a constituir los existentes [...] El 'no' puede ser un concepto, y un concepto vacío, por decirlo así, que no puede cooperar a constituir los existentes porque hace lo contrario: desconstituirlos de existentes, aunque puramente concebirlos como tales -que equivale a repetir que no puede ser más que un concepto..." (F 308). Los conceptos negativos, en cuanto conceptos, serán existentes, vale decir, serán conceptos que existen en su mera, simple y estricta calidad de conceptos, "y unos paradójicos existentes, en cuanto conceptos, y en cuanto tales integrantes de lo existente, pero negando no sólo todo lo existente menos ellos, sino incluso a sí mismos - bien que renaciendo de su propia negación..." (F 309) [al renacer como objetos del pensamiento en su posición refleja]. Si, por fuerza del existencialismo, la inexistencia de tal objeto pudo empezar sorprendiendo, no hay motivo de

8 El análisis del "no" connotante en posición directa y denotado en posición refleja se analiza también en Del hombre, p. 351 y ss., referido a la no presencia de un objeto, que tendrá relación, como veremos en su momento, con las realidades metafísicas. 
asombro "desde que se recapacita - nos dice- que entre los existentes no puede existir un existente que, para ser el objeto de 'no', tendría que ser no-existente" ( $F$ 303).

Debemos observar que el vacío con que califica el concepto negativo se refiere al concepto, que no tiene objeto correspondiente. Se trata de un vacío noético que no guarda parecido alguno con esa oquedad ontológica a cuya referencia son tan propicias las escuelas existencialistas de los más variados estilos, ni con la oquedad antropológica de la que nos habla Octavio Paz, ante cuyo vértigo el hombre tiene la experiencia de lo sagrado. ${ }^{9}$ No es una Venus de Milo a la que le faltan los brazos como dirá su contemporáneo, Eduardo Nicol, en Los principios de la ciencia. ${ }^{10} \mathrm{Al}$ contrario, el carácter afirmativo de toda realidad es lo que le plantea el problema del origen de la negación, cuyo desenlace debemos aún posponer.

¿Habremos de reprocharle a Gaos quizá por los términos, tal vez excesivos, según los cuales hay relaciones que cooperan a la constitución de los existentes, mientras hay negaciones que los desconstituyen? ¿Tienen las negaciones humanas un oculto poder hegeliano de desconstitución? ¿No sería ello otorgarles aquel valor ontológico que, según acabamos de decir, Gaos les ha querido sustraer? La indudable herencia kantiana de Gaos, manifestada en muchos de los veneros de sus obras, ${ }^{11}$ nos permite juzgar que el término constituir tiene igualmente un sentido noético y de ninguna manera ontológico. ${ }^{12}$

No debe sorprendernos que, dado el concepto de "no", el concepto de "no" carezca de objeto. Sería lo más equivalente a un pleonasmo. En cambio, sí debe sorprendernos que se dé el concepto de "no", "este insólito, extraño, casi siniestro, concepto sin objeto: ¿qué pasa con él?" (F 303).

\section{La fenomenología de la nada}

"La 'nada' es el concepto negativo de todos los sentidos de lo existente, peculiarmente sustantivado", que merece para Gaos un lugar aparte, objeto de su propio análisis fenomenológico ( $F 298$ ).

Pero nosotros juzgamos que en nuestro autor la fenomenología de la nada resulta ser, en realidad, una continuación no especialmente relevante, o en el mejor caso complementaria, de la fenomenología del "no", y que

9 Octavio Paz, El arco y la lira, Fondo de Cultura Económica, México, 1986, p. 144.

10 Eduardo Nicol, Los principios de la ciencia, Fondo de Cultura Económica, México, 1965, p. 361 .

11 Cfr. Del hombre, Lección XXXVIII, "Las antinomias", pp. 475-483.

12 La función de constituir los objetos como propia del pensarlos, se conserva también en Husserl, quien da por sentado que la conciencia posee la propiedad de ir hacia lo dado $y$ constituirlo (cfr. Leo Elders, Jean-Paul Sartre, El ser y la nada, Emesa, Madrid, 1977, p. 42). 
este carácter suyo de mera prolongación de lo estudiado en el análisis del "no" es uno de los puntos más originales y profundos del pensador discípulo de Ortega y durante muchos años seguidor de Heidegger.

Igual que "no", "nada" puede connotar o modalizar a todas las partes de la oración. ${ }^{13}$ A partir de un inventario también exhaustivo, extrae Gaos conclusiones de particular interés ( $F$ 299): unas veces, la expresión "nada" es determinante de otro concepto (nada hombre); otras, es "nada" quien recibe la determinación (no pasó nada).

Por otra parte, hay un sentido ontológico de la nada (no hay nada, no pasó nada). Tal sentido queda confirmado por expresiones de este tipo: aniquilar, aniquilado, aniquilador, aniquilación, "de inequívoco sentido ontológico" ( $F$ 299). Pero también hay un sentido axiológico: "no vale nada". A este sentido pertenecen "más castizamente" las expresiones como anonadar, anonadado, anonadamiento... (F 299).

Una persona anonadada no es precisamente alguien aniquilado, sino "abatido en grado sumo". Es por ello que no puede decirse propiamente que esté anonadada una cosa ( $F 300$ ). Gaos despeja así una injustificable mistificación entre el sentido ontológico de la nada y su sentido axiológico, lo cual constituye una fuente abundante de no pocos equívocos de sus contemporáneos.

Pero lo verdaderamente decisivo es el resultado final de esta fenomenología de la nada. En las construcciones en que "nada" es determinante se quiere decir que lo determinado no es en absoluto él mismo. En las construcciones en que "nada" es determinada, lo que quiere decirse es que "no hay ningún existente, en absoluto, o que no hay ningún existente que tenga cierto modo activo, cualitativo..." (F 300). Es decir, "nada" es un sinónimo gramatical de "no", cuya diversidad no resulta relevante y cuya construcción sintáctica se hace, en cambio, más estorbosa.

Lo peculiar de "nada" es la negación de la existencia de todos los existentes (o de alguno o algunos de ellos) ( F 300), pero no es más que una negación, que puede sustantivarse con gran facilidad, en lo que se centra su peligro. En efecto, la nada puede sustantivar el concepto "no", sin por ello denotar en posición directa un objeto, ni determinado ni indeterminado. La nada, igual que el "no", sólo puede denotarse a sí misma como objeto pero en posición refleja, esto es, no siendo otra cosa que lo que Gaos denomina, en Del hombre, objeto ideal, sin posibilidad de realidad ninguna (H 375 ss.).

13 Puede ser sustantivo ("nada hombre"); calificativo ("nada blanco"); pronombre ("nada mío"); verbo copulativo ("ahí es nada"; "no es nada"); verbo existencial ("no existe nada"); propiamente verbial ("no amarillea nada"); preposición ("se quedó sin nada"; "se hace con nada"); adverbio ("nada más"; "nada menos"; "nada lejos"; "nada temprano"), etcétera. (F 298). 
El olvido o la transgresión de que no basta ser objeto, sino que hay que serlo en posición directa para poder tener valor de realidad, es otra de las fuentes de confusión del existencialismo respecto del concepto de la nada, aunque Gaos no lo haga explícito: se limita parcamente a decir que el concepto "no" sería una crítica al nominalismo ( $F 387$ ), por cuanto que es una expresión, un nombre sin objeto. $Y$ se reduce también con sobriedad a señalar lo que le interesa desde su peculiar perspectiva filosófica, indicándolo, además, en construcción condicional: "si los conceptos sin objeto propio o no denotantes no pudieran tener su razón de ser en los objetos, sino únicamente en los sujetos, sería 'subjetiva', en este sentido, la razón de ser, en todo caso, de 'no'" (F 310).

Esta razón de ser es subjetiva, dado que, careciendo de objeto, no puede provenir de algo objetivo. Esta conclusión reafirma la situación peculiar de las proposiciones negativas, a medio camino entre las expresiones que más bien designan objetos (enunciativas) y las que más bien significan estados personales (admirativas, imperativas, dubitativas): "las negaciones [.. . ] tendrían una notificación absolutamente sui generis, en cuanto carente de designación u objeto propio..."14 Pero además las negaciones "significan directa o indirectamente un peculiar y potente complejo emocional y mocional..."15

No pretendemos afirmar que para Gaos la negación que se implica en la nada es a fin de cuentas un hecho psicológico, subjetivo, en el sentido de sentimental y caprichoso. Su intersubjetividad nos empujará hacia una etiología de más alto valor. Pero, sea como sea, no cae - según parece haber caido el existencialismo en torno suyo- en la trampa de considerar la objetividad como realidad, víctima de la paradoja por la que, como lo dice certeramente Millán Puelles, y antes lo había afirmado con énfasis el propio Gaos, "la objetualidad no implica el ser del objeto, sino del sujeto". ${ }^{16}$ La nada no es, aunque haya sido pensada (y pensada, además, como no ser).

Por este motivo, si Gaos hubiese analizado, además del fenómeno del no y la nada, en posición refleja, el acto noético de negación (y ya veremos después por qué no lo hace), también en posición refleja, podría haber dejado aún más patente que pensar en la nada implica la afirmación del sujeto, ya que el pensamiento de la nada (la negación total) adopta esta forma: "yo pienso en la nada" y, en virtud de ello, la nada total ontológica

14 José Gaos, El significado del Lambda, Homenaje a Xavier Zubiri, Editorial Moneda y Crédito, Madrid, 1970, t. I.

15 Ibid.

16 Antonio Millán Puelles, Teoría del objeto puro, Rialp, Madrid, 1990, p. 167. 
"yo pienso que no hay nada" es contradictoria, pues se está afirmando en ella la existencia del yo que la piensa.

\section{La inobjetualidad de la nada}

La conclusión de los análisis fenomenológicos del "no" relativo, y de la "nada", que es su natural prosecución, sitúan a nuestro autor en una posición divergente dentro de la corriente vitalista y existencialista contemporánea en la que se ubica. Por un lado, se coloca a contrapelo del vitalismo porque Henry Bergson no sólo le niega a la nada la posibilidad de un contenido, sino la posibilidad misma de ser idea. Bergson considera la nada como una supuesta situación previa de las cosas, digámoslo así, antes de la presunta creación de ellas. Tal problema de la nada es un pseudoproblema, según Bergson, ya que no podemos hablar del antes de las cosas. Consecuentemente, la idea de la nada es una pseudoidea. ${ }^{17} \mathrm{Si}$ la nada es impensable, si es una pseudoidea, el problema de la creación no tiene a su vez por qué ser planteado. "La palabra 'nada' no tiene significación alguna."18

Bien se ve que Bergson no ha partido del fenómeno verbal de la negación, ni del de la identidad de ésta con la nada. Si lo hubiera hecho así, no podría afirmar que el "no" no tiene ningún sentido, ya que en tal caso quien carecería de sentido sería nuestro propio lenguaje ( $\mathrm{y}$ el suyo también). ${ }^{19}$

Pero igualmente Gaos se halla frente a la posición existencialista sobre la nada, y frente a la pregunta de Martín Heidegger: "Pero ¿hay nada sólo porque hay no, es decir, la negación? ¿o más bien hay negación y no, sólo porque hay nada? Esto no está aún decidido." 20 Gaos decide la cuestión en un sentido contrario al del filósofo alemán, de cuya cárcel, según declaración suya, parece haberse liberado.

Para Heidegger, no resulta explicable la negación que hace el hombre a fin de concebir la nada: "¿Cómo podemos nosotros, seres finitos, pensar todo lo existente para hacerlo víctima de la nada?"21

Y es que para Heidegger la nada no se descubre en el fenómeno -ciertamente vulgar- de la expresión verbal, sino en un fenómeno vital: "la nada se descubre en la angustia". ${ }^{22}$ La siguiente pregunta que a partir de aquí

17 Henry Bergson, L'evolution créatrice, 14a. ed, Paris, 1913, pp. 298-323.

18 Henry Bergson, La pensée et le mouvant, 4a. ed., París, 1915, p. 108.

19 Sobre la creación como problema de lo lleno en lugar de la nada (cfr. Diamantino Martins, Bergson. La intuición como método de la metafísica, Consejo Superior de Investigaciones Científicas, Madrid, 1943).

20 Martín Heidegger, Cos'é la metafísica? (¿Qué es la metafisica?), trad. italiana Armando Carlini, Nueva Italia, Roma, 1959, p. 13.

21 Martín Heidegger, ¿Qué es la metafísica?, p. 15

22 Ibid., p. 20. 
se hace Heidegger se encararía posteriormente con la respuesta de Gaos: "¿Cómo puede la negación, este no [aportar la revelación de la nada] cuando ya, para negar, debe presuponer un negable?"23 Resolviendo el problema no ya en favor del sujeto que niega sino de la nada que nadifica: "La nada es el origen de la negación, no viceversa." 24

Se ve que Heidegger está muy lejos de pensar que la negación exprese la potencia del espíritu, como vimos que pensaba Hegel. Pero también se ve que presta muy poco valor a la negación humana, la cual resulta, finalmente, vulgar. La nada vulgar coincidiría con el concepto que Gaos tiene de la nada. ${ }^{25}$

Se ve, en fin, que aquí Heidegger está pensando que el no de nuestro lenguaje denota un objeto: la nada. Pero no se percata de que la nada, como objeto del no, no se encuentra denotada en posición directa. Es el mismo "no" sustantivado en posición refleja, dando la impresión de ser algo, a pesar del cuidado de Heidegger para no caer en el despropósito de hacer que la nada sea precisamente algo. ${ }^{26}$

Por lo que se refiere a Jean-Paul Sartre, la oposición de Gaos, que nosotros hacemos explícita, pero no él, no puede ser más clara.

En un principio, el razonamiento de Sartre parece dirigirse también en contra del "macht des negativen", el hegeliano poder de lo negativo, coincidiendo casi literalmente con Gaos: "niéguese el ser todo lo que se quiera: no se puede hacer que no sea por el hecho de que se niegue que sea esto o aquello [...] La negación no puede alcanzar el núcleo de ser del ser, que es plenitud absoluta y entera positividad. El ser es anterior a la nada [...] No hay no-ser sino en la superficie del ser". ${ }^{27}$ Pero, en realidad, la perspectiva de Sartre es, como decimos, diametralmente opuesta: "la negación no depende sólo del sujeto cognoscente: existe también objetivamente en el ser-en-sí..."28

23 Ibid., p. 25.

24 Ibid., p. 26.

25 Ibid., p. 14: "La nada es la negación pura y simple de todo lo existente."

26 Debe reconocerse que este cuidado es expreso: "la nada se descubre en la angustia, pero no como existente y menos como objeto" (Martín Heidegger, ¿Qué es la metafísica?, p. 20). "La nada no es un objeto, ni en general un existente, no se presenta por sí, al lado del existente, en el cual, sin embargo, inhiere" (ibid, p. 24). Pero lo que expresamente se niega, implícitamente se sustantiva, al afirmar que la nada produce determinados efectos: la nadificación, la negación humana, la inherencia misma en el existente, etcétera.

27 Jean-Paul Sartre, El ser y la nada, trad. Juan Valmar, Losada, Buenos Aires, 1966, pp. 51 56. Leo Elders, Jean-Paul Sartre... p. 65: "Dada su plena positividad, el ser no puede producir la nada" (ibid.).

28 Jean-Paul Sartre, op. cit., p. 44. Cfr. ibid. pp. 41-44: "Lo que el ser será se recortará necesariamente sobre el fondo de lo que el ser no es". Idem. pp. 44-45: "El no-ser es increado; es una presencia perpetua en nosotros y fuera de nosotros. El no-ser infesta el ser." Ibid. pp. 57- 
En cambio, la actitud adoptada por Gaos ante el carácter radicalmente subjetivo de la negación, dado que no hay objeto real al que la negación corresponda, resulta coincidente con el punto de vista más tradicional de la metafísica.

Tomás de Aquino se muestra partidario de la inobjetualidad de la nada, precisándola en estos términos: la nada puede pensarse como un ente de razón (secunda intentio), pero realmente ni es de suyo nada, "ni pone ni determina nada en la realidad". ${ }^{29}$ Traducido a los términos de nuestro filósofo, la nada es inobjetual porque carece de objeto determinado en la realidad, y porque no introduce nada en ella. Los comentadores tomistas se encuentran en esto de acuerdo: "ser ciego no es ser nada [...] que la nave no tenga timonel no es ser algo" (Cayetano, In de ente et essentia).

¿Cómo se conoce, pues, el no-ser y la nada, si no son nada, ni ponen nada en la realidad? Es aquí donde la coincidencia con Gaos se torna prácticamente en identidad, porque la nada puede pensarse gracias a que el sujeto pensante le otorga la objetividad que le falta: "el no ser no cuenta en sí mismo con algo por lo que sea susceptible de conocerse, sino que se conoce en la medida en que el entendimiento lo hace cognoscible". ${ }^{30}$ "El entendimiento no puede entender el no-ser sino fingiendo el mismo ser de alguna manera." 31 Gaos diría que este fingimiento del ente, este concebir el no ente al modo del ente, no siéndolo, es la operación mental que coloca los conceptos en posición refleja, sustantivándolos como si fueran objetos, cuando en la realidad no lo son.

Sólo de esta manera es posible aceptar la propuesta de Gaos: por un lado, admitir que el no-ser es nada, o, más rigurosamente, que la nada es

62: "Podemos comprobar que la negación se halla presente en la realidad [...] [La nada] está dispersa por el ser, sostenida por el ser." Hasta alcanzar una objetividad ajena ya al sujeto que niega: "la nada sólo puede darse en el seno mismo del ser, como un gusano" ibid.

29 Tomás de Aquino, Summa theologiae, I, q. 17, a. 4, c: "Neque ponit aliquid neque determinat sibi aliquod subiectum." Para Aquino se dan así tres niveles en el no-ser: el más profundo -n el que hay coincidencia con Gaos- es el de la negación, que, como dijimos, ni pone, ni determina; la privación, que no pone tampoco nada, pero determina al sujeto al que le corresponde la privación, como cuando se dice que este hombre es ciego, siendo así que por naturaleza le compete gozar de la vista; y el contrario (por ejemplo, lo negro como contrario de lo blanco) que añade o pone algo y además determina al sujeto: cuando decimos de él que es negro, estamos afirmando una especie determinada de color (cfr. ibid.). No podemos explicar aquí que estos niveles de no ser se encuentran implicados en la fenomenología del "no" hecha por Gaos (cfr. además, Aristóteles, Metafisica, IV, III, 1004a 5).

30 Tomás de Aquino, Summa theologiae, I, q. 16, a. 3 ad 2.

31 Tomás de Aquino, De natura generis, cap. I. En esto también concuerdan los comentadores de Tomás de Aquino: "se llama [...] ente de razón [...] al que se concibe al modo del ente no siendo en sí ente" (Juan de Santo Tomás, Lógica, II, q. 2, a. 1). 
sinónimo del no-ser (cfr. F 385), y, por el otro, que el no ser sí lo podemos concebir. ${ }^{32}$

Queda manifiesto que la sustantivación de la nada es una operación sólo mental: la realidad no cambia. De lo contrario, esas dos minúsculas letras ("no"), supuesto que pueden connotarlo todo trascendentalmente con su negación, harían posible "la aniquilación de los existentes designados por las expresiones afirmativas, y aniquilación sin duda física" ( $F 350$ ).

Hay otro punto más importante en el que la posición de Gaos y la filosofía aristotélica guardan una estrecha consonancia, aunque se muevan en parámetros básicos muy diversos. Jacques Maritain y José Gaos coinciden en su posición frente a Bergson, explícitamente el primero e implícitamente - como ya se dijo- el segundo.

Cuando Bergson afirma en La pensée et le mouvant que la palabra nada no tiene significación alguna, se presenta la cuestión acerca de la causa por la cual, sin embargo, siendo una pseudoidea, es pensada por el ser humano. Si la empleamos, se contesta Bergson, es sólo por la necesidad social del lenguaje. Cuando decimos que no hay nada, damos a entender que aquello que hay no nos interesa: "la irrealidad de una cosa consiste en su expulsión por otra". ${ }^{33}$ La nada indica, por así decirlo, la desaparición de una cosa. Pero una cosa no desaparece sino porque otra la sustituye: supresión (y, por tanto, nada) significa lo mismo que sustitución, real o imaginaria. ${ }^{34} \mathrm{La}$ idea de la nada se origina, pues, por un proceso psicológico y afectivo, porque no encontramos aquello que buscamos: en su lugar hemos encontrado otra cosa, y como seguimos atendiendo a la realidad desplazada decimos de ella que "no es". 35

Respecto a este planteamiento, Maritain concede que generalmente hay un juicio que puede desplazar a aquél en el que hacemos una negación. Pero hay veces que este juicio no existe: si yo digo que "este hombre no tiene hijos", no puedo significar ni determinada ni indeterminadamente que tal hombre tiene otra cosa distinta de sus hijos. ${ }^{36}$

¿Cuál es, entonces, el contenido de la idea del no-ser y de la nada, si no admitimos ni que tenga como contenido un objeto en posición directa ni que tenga como contenido el objeto que ha desplazado a aquél del que decimos

32 En lo que coincide, a su vez, con Jaime Balmes, Filosofía fundamental, t. II, p. 125.

${ }^{33}$ Henry Bergson, Levolution créatrice, p. 306.

34 Henry Bergson, La pensée et le mouvant, p. 108.

35 Este análisis coincide en apariencia con el que veremos después realizado por Gaos -que emplea también los conceptos de desaparición y desplazamiento- y también con los que realiza Sartre, pero se advertirá que la posición de Gaos sigue distinguiéndose claramente de la de ambos pensadores franceses.

36 Jacques Maritain, La philosophie bergsonienne, 2a. ed., París, 1930, p. 38. 
ahora que no es o que es nada? Es a esta pregunta crucial a la que responde Maritain coincidiendo con José Gaos: la idea negativa, la negación, "es el signo que afecta el contenido de la idea positiva; no es el contenido mismo: lo que le es propio es el signo negativo y no el contenido, que es propio de la idea positiva". 37

A su modo, en esta manera de decir vemos cómo "no" es el signo que afecta - connota - al objeto de la idea afirmativa a la que afecta, connota o modula de "no", pero no puede denotar un contenido propio, un objeto que le corresponda, ya que lo suyo es sólo connotar negativamente los conceptos que denotan objetos y los objetos denotados por ellos.

\section{Importancia metafisica del prefijo in-}

A pesar del cuidado puesto en una fenomenología exhaustivamente inventariada, Gaos - advertida o inadvertidamente- omite el análisis y la comparación de dos modos negativos que resultan clave en el manejo de la negación. Se trata del modo diverso de negar que se encuentra implicado en estas dos negaciones: $A$ no es $B$ y $A$ es no $B$. Bajo ningún aspecto se trata de juicios idénticos, especialmente si se los considera, más que copulativos, también existenciales. Én este caso la segunda proposición negativa incluye una afirmación muy seria para el sujeto $A$ : que existe, aun no siendo $B$. En cambio, en la primera proposición ( $A$ no es $B$ ) no decimos expresamente que $A$ es o existe, sino que nos limitamos a la somera negación de lo que no es, $\mathrm{y}$, en todo caso, a su mera posición mental.

Esta distinción es importante para la metafísica, ya que de los entes xoriston o separados de la materia, lo que puede decirse se desliza más bien por la vertiente del $A$ es no $B .{ }^{38}$ Metafísicamente podría probarse la existencia de tales entes, aunque no resultaran definibles conceptualmente: podemos

37 Ibid., p. 43. Que las ideas negativas tienen su contenido en la ideas positivas, tal como Gaos lo señala, es un lugar establecido en la escolástica más tradicional: la privación del ente se funda en el ente (Tomás de Aquino, Summa theologiae I, q. 11, a. 2, ad 1. "Siempre en el mundo real la negación se funda sobre alguna afirmación, que es como su causa"; Summa theologiae I-II, q. 72, a. 6. "Naturalmente la afirmación es anterior a la negación..."; Summa theologiae, II-II, q. 122, a. 2, ad 1.) Este fundamento es fundamento en el orden de la causa formal (el contenido de la noción positiva especifica o determina la negación). Esto es lo que inclina a Gaos a pensar que también los conceptos contradictorios (un cuadrado redondo) son concebibles, porque cada uno es específicamente distinto de los demás conceptos contradictorios ( $H$ 356). Pero esta justificación en el orden de la causa formal no resuelve aún el problema de la etiología de la negación en el orden de la causa eficiente.

38 En El significado del Lambda, Gaos considera lo separable o lo separado como una de las siete ideas centrales o dominantes en el libro Lambda de la Metafísica de Aristóteles, que es, como se sabe, un compendio de la teodicea aristotélica, y que lo escogió en esa ocasión como tema de estudio debido a "su importancia histórico-filosofica" (ibid. p. 579). 
conocerlos sólo diciendo lo que sabemos que no son, es decir, diciendo que sabemos que son, pero no qué son, sino qué no son. ${ }^{39}$

Podrían hacerse muchas hipótesis para explicar este olvido de Gaos en asunto de tanta importancia. No encontramos en sus escritos una justificación expresa. Puede suponerse que considerara que aquellos objetos de los que no pudiera decirse qué son, sino sólo qué no son, no resultan susceptibles de ser tratados fenomenológicamente; o podría conjeturarse que se encontrara afectado por la opinión de Imanuel Kant acerca de esos juicios negativos que llama infinitos, los cuales no permiten incrementar, según él, el concepto del sujeto en lo más mínimo, y determinarlo afirmativamente. Si digo que el alma es inmortal, lo único que he logrado es eliminar del espacio infinito de los seres la pequeña parte que corresponde a los mortales, pero aún quedan muchas otras partes por eliminar: aunque lo hiciera mediante otras negaciones, el alma quedaría aún en el espacio de los infinitos posibles. ${ }^{40}$

No podemos entrar ahora en este problema, y hemos de limitarnos a decir que si afirmamos el alma como un ser inmortal, estamos muy lejos de considerarlo como posible si al es del juicio con que hemos hecho esta afirmación (es inmortal) le damos la carga existencial que le corresponde.

Pero la consideración de la importante estructura lógica $A$ es no $B$, en la que se afirma la existencia de $A$, si bien no se dice qué es, fuera de que es y del atributo que se le niega, se encuentra implícitamente contenida en la identificación que hace José Gaos entre el "no", como negación fundamental, y el prefijo in- que es para él del todo equivalente. El haberse empeñado en llevar a cabo una fenomenología de la expresión verbal de manera completa tiene aquí sus consecuencias favorables.

Ésta es la condición del prefijo in- hallada en los ejemplos manejados por Gaos al hacer su inventario de los fenómenos de la expresión verbal: el in-, como el "no", como el ninguno y como el nada, recibe la denominación de negación total (F 294), y se equipara con la nada misma, según hemos visto, cuando se aplica al existente, en la forma de inexistente o, incluso, de inexistencia ( $H$ 351), que es la sustantivación del adjetivo inexistente, como la nada lo es del "no".

De este modo, abre Gaos la posibilidad a una metafísica de Dios, aunque tenga ese carácter que hemos llamado negativo, según el cual podríamos saber de Dios los atributos que no le pertenecen. Gaos mismo no sólo abre la

39 Tomás de Aquino, Summa theologiae, 1, q. 3, Introducción: "Habiendo conocido la existencia de algo, resta investigar cómo es ese algo. Pero como de Dios no podemos saber qué es, sino qué no es, no podemos considerar de Dios cómo es sino más bien cómo no es."

40 Kant, Crítica de la razón pura, Analítica Trascendental, libro primero, cap. primero, 2a. sec., Porrúa, México, 1987, p. 67. 
puerta sino que, en algún sentido, aunque todavía tímido, como es su actitud siempre que se asoma a la metafísica, se introduce en ella en El significado del Lambda. Cuando se da a la tarea de explicar los seis conceptos capitales o dominantes del libro XII de la Metafísica de Aristóteles, incluye los términos infinitud, infinito, inmutabilidad, indivisible e inmoble. ${ }^{41}$

En este sentido, se asemeja menos a Kant, quien no admite la predicación de atributos negativos porque dejan en la indeterminación al sujeto del que se predican, ${ }^{42}$ y más a Aquino, quien no se impide a sí mismo una metafísica negativa de Dios, aunque sea consciente de sus limitaciones. ${ }^{43}$ Quizá por esto mismo, para Gaos, en las proposiciones negativas puede reconocerse "la vacilación intelectual". ${ }^{44}$

\section{La negación práctica}

El acierto de que Gaos haya comenzado su fenomenología de la negación asumiendo como objeto la expresión verbal, y no otros de los muchos fenómenos antropológicos posibles, hace más fácil y breve el análisis de la que denomina negación práctica, a diferencia de la negación verbal que podría considerarse sólo como "negación puramente teórica" (F 316) y, generalmente, objetiva, en el sentido de no ser parte de ningún sujeto ( $F$ 315). La negación comienza a adquirir la tonalidad de práctica cuando se refiere a un sujeto, sea ajeno o sea propio, como es "negarse a sí mismo" (F 315), "autodenigrarse, menospreciarse a sí mismo hasta lo patológico de los complejos de inferioridad, autoenvilecerse" ( $F 316)$. Es importante en la negación práctica atender al destinatario del "no", que no puede ser más que un sujeto que comprenda el concepto, ya que el "no" carece de objeto (F 323).

A veces, sin solución de continuidad, se llega a la tesitura de que ese objeto negado de pensamiento o de palabra resulta objeto de acción: "negar lo que se piensa diciendo lo contrario de lo que se piensa o no diciendo (lo) [...] la elocuencia del silencio" (F 316), negar lo que se siente o quiere,

41 José Gaos, El significado del Lambda, p. 579.

42 Cfr. Kant, op. cit.

43 Tomás de Aquino, Summa theologiae, I-II, q. 100, a. 7 ad 3 um: "Si siempre a una afirmación sigue la negación de su opuesto, en cambio a la negación de un opuesto no siempre sigue una afirmación positiva. En efecto, si es blanco, no es negro, pero del hecho de que no sea negro no se sigue que sea blanco, porque la negación es más extensa que la afirmación." Concuerda Aquino, en esto, pues, con Kant, para quien lo negativo nos coloca ante una "ilimitada extensión" — cfr. Kant ibid.--; pero no por ello guarda silencio, porque sabe que las "realidades primeras y simples se notifican mediante la negación" (Tomás de Aquino, Summa Theologiae, I, q. 33, a. 4).

44 Gaos, El significado del Lambda. 
negar el objeto de una acción material, como una limosna, o de una acción inmaterial, como una recomendación, negar el asentimiento a lo que se ha dicho, negar la aprobación a lo hecho, negar un sentimiento, negar el amor o la obediencia... blasfemar contra Dios y profesar el ateísmo ( $F$ 316); la negación práctica de la práctica, rectificando lo mal hecho; negar y renegar con obstinación ( $F 318$ ).

Al lado de estos ejemplos de negación práctica, de la que Gaos hace un análisis mucho más extenso que el aquí presentado muy condensadamente, no podemos evitar que aparezca el paralelismo con lo que podrían denominarse negaciones prácticas en Heidegger: "la dureza de la acción hostil y la aspereza del execrar, el dolor de rehusar, la inexorabilidad de prohibir, la anarquía de renunciar". 45

En este paralelismo se nos hace evidente una mayor subjetividad en las negaciones prácticas ejemplificadas por Heidegger y una mayor objetividad en las ejemplificadas por Gaos. Esta objetividad viene dada como consecuencia de la atención preferente que Gaos prestó en su momento a la negación de las expresiones verbales —que son, por definición, más objetivas e incluso intersubjetivas- como instrumentos de comunicación que les corresponde ser. Por esto, para Heidegger, "la negación [intelectual y verbal] no tiene capacidad reveladora de la nada", pues el pensamiento tiene primero que mirar el "no" antes de pronunciarlo. ${ }^{46}$

No es extraño - sobre todo ahora, en contraste con la negación práctica de Gaos- que se haya dicho, con motivo del centenario del nacimiento de Heidegger, que estamos ante un metafísico romántico que interpreta los estados de ánimo en clave de experiencia metafísica, la cual, aunque pugne por expresarse en conceptos e ideas, mantiene siempre en Heidegger la penumbra de la referencia al sentimiento.

Por su lado, en el análisis de las negaciones prácticas, Gaos no tiene que hacer un esfuerzo para expresarse en conceptos e ideas porque ha partido precisamente de ellos, aunque pierda sin duda la cualidad sugestiva de un procedimiento, diríamos, más atractivo y sentimental.

\section{La negación práctica en la voluntad}

Gaos reserva un espacio peculiar para el estudio de las negaciones del querer humano. Se detiene de manera especial en el hecho de que la voluntad pudiera tener por objeto el ser o el no ser, o, al menos, la existencia o

45 Martín Heidegger, ¿Qué es la metafísica?, p. 27.

46 Ibid., p. 25. No consideramos aquí, porque nos pondría fuera de contexto, esa vivencia heideggeriana de "encontrarse el ser existencial mantenido dentro de la nada fundada sobre la angustia..." (Ibid., p. 27.) 
inexistencia de un existente. Este hecho recibe la denominación de "capital, o quizá mejor, radical" ( $F 320$ ), fenómeno que se vincula con el amor y el odio, sin caer en la banalidad contemporánea según la cual amar sería algo antropológicamente positivo y odiar algo negativo, ya que se podría odiar el bien y amar el mal (ibid.).

Aparece ya aquí un primer atisbo de la solución etiológica de las negaciones: el odio, entendido como querer la inexistencia de algo o de alguien, pudiera ser el motivo de la negación radical, de manera que la causa eficiente de ésta no se encontraría en el entendimiento, sino en la voluntad, por donde brotaría de nuevo en Gaos el vitalismo que hubiera quedado subyacente en sus análisis, en apariencia vitalmente asépticos, sobre las negaciones verbales. Esto justificaría por segunda vez la aseveración de que las expresiones de la negación estarían en un terreno intermedio entre las proposiciones enunciativas, más designantes de los objetos, y las proposiciones admirativas, interrogativas e imperativas, más significantes de la interioridad del sujeto. Las proposiciones negativas, no teniendo objeto propio, dijimos, requieren de una causa subjetiva, que se atisba ya como posible en el odio y las emociones o mociones que la acompañan o se le asemejan. ${ }^{47}$ La voluntad, pues, en su versión operativa fundamental -más la de querer que la de amar - toma carta de naturaleza en el territorio de la negación.

Que el acto voluntario pudiera ser el origen y la causa de la negación es algo que ya fue vislumbrado por Roland Gosselin, para quien, igual que para Gaos, la noción del no-ser supone el acto de negar, acto gracias al cual el espíritu tiene el poder de concebirlo con un valor objetivo (no real, sino objetivo). ${ }^{48}$

Pero, a diferencia de Maritain, ${ }^{49}$ y en consonancia con Gaos, la mera idea positiva que es negada en el acto de negación, no explica por sí sola la negación misma. Explica sólo lo connotado, lo modulado por el "no", pero queda en el vacío la causa por la cual el entendimiento niega lo que concibió (máxime si lo concibió, como veremos en el caso de Gaos, para negarlo). "Para comprender inmediatamente la negación —dice R. Gosselin— no de-

47 Esta idea - la importancia del odio en la antropología de José Gaos- es tratada por él en las últimas lecciones de Del hombre, pero no podemos detenemos ahora en ella, pues guarda un nexo directo con asuntos diferentes de la negación.

48 Roland Gosselin, "Essai d'une etude critique de la connaissance", en Biblioteque Thomista XVII, Paris, 1932, p. 85.

49 Jacques Maritain, De Bergson a Tomás de Aquino, Buenos Aires, 1946, p. 28: "el contenido de la nada es el ser afectado por el signo de la negación, es el no-ser. Basta la actividad propia de la inteligencia para formar tal idea"; La philosophie bergsonienne, p. 38: "un juicio negativo [...] no supone más que él mismo y la actividad del espíritu". No tiene caso buscar en la negación algún elemento extraintelectual (ibid., p. 46). 
be hacerse intervenir antes de ella más que el ser mismo y su afirmación." 50 Efectivamente, en el orden de la causa formal o especificativa, la negación no tiene más contenido (más connotación dirá Gaos) que la idea positiva; pero carece de contenido propio (no posee objeto que pueda denotar). Esto es lo que le hace a R. Gosselin, igual que a Gaos, preguntarse por la causa eficiente $(0$, si se quiere, el motivo que posee el entendimiento para negar lo que piensa primero como afirmativo). El punto preciso y exacto de la cuestión es éste: ¿qué relación tiene el acto de la negación del ser con el acto de su afirmación?, ¿por qué el entendimiento niega lo que afirmó? Lo que Roland Gosselin insinúa con timidez ("quizá el acto de negar el ser [...] corresponde al orden afectivo y voluntario más que al orden intelectual"), ${ }^{51}$ Gaos lo afirma con seguridad y enfáticamente, al punto de admitir la posibilidad de que los conceptos de ser o no ser, de existencia o inexistencia "sean oriundos de la voluntad misma", siendo como es "la moción de la subjetividad que da a toda ésta su característica mocionalidad" ( $F$ 321). ${ }^{52}$

Pero el acto de negar con la voluntad se nos complica, porque se desdobla en dos posibilidades diversas: no querer algo y querer que algo no sea como es, o, dicho de otra manera, no querer que algo exista o querer que algo no exista (F 320).

Parece que el no querer que es una forma negativa de menor calado que el querer que no (ibid.), ya que la primera puede entenderse como falta o vacio de toda volición; pero bien entendido, igualmente que el querer que no, el no querer que puede adquirir el carácter de "una verdadera nolición muy determinante relativa a un objeto" ( $F 320$ ), de manera que la causa de la negación podría ser tanto la volición (querer que no) como la nolición (no querer que), como acto volitivo y no como ausencia del ejercicio de la voluntad (ya que la ausencia de ejercicio de la volición no sería causa de nada).

Pero lo importante de este análisis de la negación práctica, referida al acto de la voluntad, es que la volición y la nolición negativas no sólo son causa, evidentemente, de la negación práctica de la propia voluntad, sino que pueden serlo también de la negación intelectual. Éste es el dato nuevo (aunque ya antes lo hubiera vislumbrado tímidamente el tomismo contemporáneo) que Gaos aporta a la fenomenología de la negación práctica.

Quedaría en suspenso "¿cuál sería [...] la situación más negativa posible?: ¿aquélla en que un sujeto se niegue a sí mismo en su integridad y, por

50 Roland Gosselin, "Essai d'une etude critique de la connaissance", p. 85.

51 lbid.

52 Gaos distingue entre moción que es el acto propio de la voluntad, y emoción, que es el acto propio de los sentimientos, afectos, pasiones, etcétera. 
ende, en toda forma, a Dios? [...] ¿aquélla en que un sujeto quiera la nada absoluta, por odio a todo, radicalmente, quizá a sí mismo?..." ( $F$ 324).

Tal vez, sin embargo, querer y no querer no sean las causas únicas de la negación. Podrían serlo también la presencia y ausencia del objeto. Lo cual nos introduce en la fenomenología del no existencial como la que antes se realizó del no relativo.

\section{Fenomenología del "no" existencial}

Dijimos que el verbo ser desempeña un triple papel en nuestras proposiciones, lo cual da lugar a tres tipos diferentes de negación: relativa, existencial y verbial ( $H$ 330). El estudio de la negación relativa (negación del es establecido como relación entre sujeto y predicado) fue principal para la fenomenología del no, labor llevada a cabo en las lecciones sobre la negación recogidas en De la filosofía, que resumimos en páginas anteriores.

Analicemos ahora la negación que se deriva del ser no ya como relación o cópula, sino como existencia. El estudio comienza, igualmente, por la fenomenología de la expresión verbal: "Al decir que esta mesa 'existe': ¿qué quiero decir?" (H 330). "Que [. . . ] la existencia de esta mesa es su presencia aquí, ahora, para mî” (cfr. H 330).

Se ha de reconocer que este comienzo de la fenomenología de la negación existencial difiere respecto del inicio de la fenomenología de la negación relativa. En ésta se comenzó simplemente con la expresión esta hoja no es amarilla, cuyo significado no resulta discutible, asumiendo ya de principio que el ser (es) mencionado expresa una relación. Pero el significado de la expresión verbal esta mesa existe (o no existe), resulta en parte igual y en parte diferente respecto de esta hoja es amarilla (o no es amarilla).

Resulta igual porque Gaos ha escogido - sospechamos que a propósitodos objetos inocuos - esta hoja y esta mesa- con la finalidad de hacer más frío y distante el objeto, no sea que despierte emociones que fueran a mezclarse en el análisis de la expresión. Precisamente porque sabe que la intervención de esas emociones es inevitable, pone especial cuidado en hacerlas explícitas a fin de excluir, como quería Husserl, todo lo que sea subjetivo, y adoptar una actitud teórica. Se evita así hacer una fenomenología de los estados de ánimo, como Millán Puelles le ha reprochado a Heidegger, o sentirnos autorizados a transferir a la realidad nuestras esperanzas y emociones, como Elders le reprocha a Sartre, quien termina identificando la esencia de las cosas con el significado que nosotros les otorgamos. ${ }^{53}$ (Para Gaos las esencias se designan y las emociones se significan: se trata de dos objetos noéticos diferentes, a los que corresponden dos diferentes noesis). 
Pero el inicio de la fenomenología del "no" relativo —esta hoja no es amarilla - resulta diferente del inicio del "no" existencial —esta hoja no existe. Porque todos nos encontramos concordes con lo que significa el predicado amarillo, pero hay discordancias en el significado del atributo existe, incluido en la proposición "esta mesa no existe".

La historia de la filosofía nos muestra que se dan dos sentidos básicos (al menos) al término existencia, que corresponden - más o menos directamente- a aquellos dos diversos sentidos del ser (ser veritativo y ser como acto propio) que encontramos en la Metafísica de Aristóteles (VI, 4, 1027b 30; XI, 8, 1065a 20-24). La existencia tiene el significado, favorecido aquí por Gaos, de algo que me está dado como presente; pero igualmente posee el sentido de algo dado en sí mismo, exterior y separado, con independencia del sujeto que lo piensa. La existencia en cuanto propiedad correspondiente a lo que se me presenta, tiene la ventaja de su indubitabilidad: si está presente no puedo dudar de que existe. La existencia como propiedad correspondiente a las realidades que son en sí mismas y no pensadas por un sujeto ofrece la ventaja de que - precisamente al contrario- si existen sin relacionarse conmigo realmente existen en sí. La primera versión apela a la seguridad del sujeto que afirma algo como existente; la segunda versión, a la realidad de la existencia del objeto afirmado.

Estamos, pues, ante una opción que sin duda Gaos ha tomado implícitamente al iniciar esta fenomenología del no existencial. Haber escogido la alternativa de la presencia ante el sujeto con hegemonía sobre la independencia del objeto, habrá obedecido a motivos que se derivan precisamente de su reiterada posición fenomenológica, pero Gaos no ha sido explícito en este punto, aunque los dos sentidos de existencia serpean, como veremos, en sus lecciones sobre la negación.

La presencia del objeto ante el sujeto no solamente es fenoménica, sino que se erige precisamente como el fenómeno. En cambio, la independencia del objeto respecto del sujeto no sólo no es fenoménica, sino que puede verse como la antítesis de todo fenómeno. Nos hallamos, en el fondo, frente a la contraposición del para sí del fenómeno (en relación con el sujeto) y el en sí de la cosa (en relación consigo misma) ${ }^{54} \mathrm{El}$ primer sentido de existencia puede denominarse fenoménico, mientras que el segundo podría recibir el de metafísico.

El sentido fenoménico de existencia parece incorporar su propio criterio de evidencia, ya que si está presente, no hay duda de que existe. Por contraposición, la verdad de la existencia del en sí, debido a su independencia

54 Nada tiene que ver este par de conceptos (para sí y en sí) con los analizados por Sartre en El ser y la nada, por ejemplo, en las pp. 253 y ss. 
respecto del sujeto, no resulta evidente, y habría que llegar a él a partir del fenómeno.

Pero, al mismo tiempo, adoptar exclusivamente el concepto de existencia como lo dado en presente, puede entrañar el peligro de confundir lo que es meramente objeto - dado también como presente- con lo que es una positiva realidad independiente de su ser dado en mi conocimiento (en la que interviene ya el sentido de realidad metafísica). ${ }^{55}$

Debe decirse que la concepción de la existencia como presencia no es en modo alguno exclusiva de la fenomenología, y menos aún de la fenomenología a la rigurosa manera de Gaos. Pues también en este punto nuestro filósofo entronca con corrientes filosóficas de raigambre escolástica. ${ }^{56} \mathrm{Gaos}$ no es sólo fenomenólogo.

En la primera mitad de este siglo un conjunto de pensadores de Lovaina, sin duda bajo un influjo husserliano, llevó a cabo estudios, muy similares a los de Gaos, acerca de la existencia como presencia. La estrecha relación entre la una y la otra no los lleva a afirmar su identidad, lo que tampoco sucede en nuestro filósofo, pero sí a percatarse de que la presencia es un criterio de seguridad de la existencia en el que habrá a la postre que desembocar. Porque "si no es suficiente pensar el ser para que exista, si lo percibimos existe a ciencia cierta". 57

Además, la presencia de lo existente conlleva el carácter de primariedad: "el ser hace su epifanía ante la inteligencia desde sí mismo, mostrándose primeramente como presencia de algo". ${ }^{58}$ Junto con ello, la presencia del ser es ineludible y dominadora: "Hay una presencia que se impone [...] a nuestra conciencia, que llena a la vez todos nuestros sentidos [...] que nos golpea." 59

Esta presencia indubitable, primaria, ineludible y dominadora, manifestativa de la existencia, llega a recibir el calificativo de "identidad fundamen-

55 No es el momento ahora para explicar que Gaos sortea este peligro mediante dos categorías noéticas omnipresentes tanto en Del hombre como en De la filosofia: el concepto ideal, frente al concepto de lo real; y el percepto, frente al sólo concepto mental ( $H 340)$.

56 Cfr. especialmente, Noël, Le realisme inmediate, Biblioteca del Instituto Superior de Filosofía, Lovaina, 1938; Roland-Gosselin, "Sur la notion de présence en epistémologie", en Revista des Sciences Philosophie et Théologie, 1928, p. 80.

57 Van Riet, "Philosophie et existence", en Revue Philosophie, Lovaina, 1948, p. 369.

58 Juan R. Spich, "Estudio preliminar del tratado De ente et essentia de Tomás de Aquino", Buenos Aires, 1940. (Cfr. J. Maritain, Siete lecciones sobre el ser, Buenos Aires, 1943.)

59 Noël, "La présence inmediate des choses", en Revue Neoscolastique de Philosophie, Lovaina, 1927, p. 180 (cfr. también pp. 145-162). Quizá el antecedente de Noël pueda encontrarse en Zigliara, Essais sur les principes du traditionalisme, traducción francesa A. Morgner, Lyon, 1880 , p. 89 , en donde se dice que para tener el conocimiento de la existencia, la presencia, sea directa o indirecta, es suficiente. 
tal, viendo que aquello que tengo yo presente es algo que existe; aquello que yo experimento sensiblemente, que actúa en mí, es". ${ }^{60}$

Estos pensadores sedicentes neoescolásticos son paralelos a Gaos porque resaltan la índole existencial de la presencia de las cosas, sin suponer que la existencia se agota en su mero presentarse. No se trata, pues, de un idealismo empirista, al modo de Berkeley, en donde el esse se conmensura con el percipi. El percipi, el ser percibido, más que el contenido medular del esse, o existencia, es su signo, su patentización o criterio: si se percibe es que existe. ${ }^{61}$

\section{La estructura de la presencia}

La presencia en que consiste o en donde se patentiza la existencia encierra para Gaos varias "relaciones componentes" ( $H$ 335-336; cfr. 331 y 341): a) de lo presente, b) en sí mismo, c) en el lugar y tiempo del sujeto, d) entre los demás presentes integrantes del lugar, e) para un sujeto.

\section{a) La presencia es, evidentemente, la presencia de lo presente}

Entre lo presente, la presencia y la existencia de lo presente se da una suerte de identidad, de manera que el pensamiento de que hay una presencia no presente resulta contradictoria ( $H$ 348), y como la presencia es inequívocamente manifestativa de la existencia (pero no al revés: la no presencia no es manifestativa de inexistencia), por ello mismo es también contradictorio el juicio "esta mesa no existe" ( $H 343$ y 344), pues el esta de la mesa nos diría que la mesa se encuentra presente, y el no existe de ella, que no se encuentra presente.

Sin embargo, lo presente de un modo rigurosamente fenomenológico sólo es válido en el instante del presente, pero no en el inmediatamente pasado ni en el inmediatamente futuro. Tiene por ello que arbitrar la distinción entre presencia presente (la de este instante) y presencia representada (la del instante inmediatamente anterior) que conserva, digámoslo así, una inercia de proximidad temporal, y la del instante inmediatamente posterior que anticipa también una temporal inminencia ( $H$ 338). El concepto de presencia representada se otorgará después no sólo al pasado y al futuro inmediatos, sino al pasado $\mathrm{y}$ al futuro infinitos.

60 Geiger, "Philosophies de l'essence et philosophies de l'existence", en Congreso Internaciònal de Filosofía, Barcelona, 1948.

61 José Gaos, $H$ 341: "Hay también la idea de que la presencia no sería la existencia sino el criterio de ésta." 
b) Lo presente tiene esta condición en sí mismo

No es de admirar que Gaos encuentre en este en sí mismo especiales dificultades. Aparece subrepticiamente la dicotomía de la existencia como presencia y de la existencia como en sí, esto es, como acto propio de la realidad que se encuentra fuera de sus causas y de la nada, según dice la fórmula clásica.

Porque la realidad puede hallarse al mismo tiempo en sí y presente. Tal parece ser el caso de esta mesa. Sin embargo, al admitir este en sí de la mesa dentro de la estructura de la presencia, equivale quizá a extender un pasaporte fenomenológico a lo que pudiera tal vez ser metafísico. Gaos no duda, sin embargo, en incluirlo como ingrediente esencial de la presencia: "Si está presente, lo está en sí misma..." (H 336). Por tal razón, a veces nos inclinamos a pensar, sin que tengamos un texto cierto en que apoyarnos, que el en sí mismo adscrito por Gaos aquí a lo presente tiene más bien el sentido de por sí mismo: la mesa estaría presente por sí misma y no por un intermediario ni por una representación suya.

Pese a tales suposiciones, es verdad que José Gaos, en este contexto, hace equivalentes el en sí de la mesa presente y el en sí como existencia metafísica ( $H$ 354-355).

La dificultad del en sí presente (si no estuviera en sí no estaría presente, pero el en sí es un plus que va más allá de la presencia) se resuelve a medias apelando no ya al en sí metafísico (que es lo que ha de resolverse) sino al en sí psíquico. El sujeto puede concebir la identidad de sus actividades y de su presencia ante sí mismo, y después generaliza esta identidad suya "a las demás sustancias..." ( $H$ 354). Habrá una analogía, pues, entre el en sí mismo del hombre como sujeto psíquico y el en sí mismo de la mesa como objeto físico. Legítimamente podremos preguntarnos si esta extensión del sí mismo por círculos concéntricos, a partir del fenómeno humano, es a su vez legítima; preguntarnos si no hay aquí una quiebra en la línea que Gaos parece haber intentado seguir: que los sentimientos del hombre no nos hagan incurrir en el error de transponerlos inadvertidamente a la realidad física circundante.

Personalmente no dudamos de que la mesa que Gaos tiene delante en sus lecciones posea un en sí; pero sí dudamos de que la vía emprendida a partir del sujeto psíquico sea válida para llegar a él. Gaos no considera que sea un camino del todo franqueable, dado que el problema del en sí de lo presente queda aún irresuelto para él, y deberá hacer nuevos intentos para su acceso.

Hay algo claro: en el sujeto ante el que ocurre la presencia se da siempre -en su vida consciente- una conciencia de su presencia ante él: hay aquí una simultaneidad y transparencia del en sí y el para sí, que se llama re- 
flexión: "En la presencia de mí para o a mí el primer relato soy yo en cuanto presente y el segundo yo en cuanto presencial" ( $H$ 335). ¿Podemos suponer en la mesa, no ya la conciencia, sino una existencia de su en sí, aunque no sea consciente de ella? Contestar esta pregunta de modo positivo sería, de alguna manera, admitir un en sí metafísico. Pero hacerlo negativamente daría pie a la negación del en sí que es "la más perturbadora de las negaciones" como ha dicho Elena Orozco, coetánea y colega de Gaos en la Universidad Nacional Autónoma de México. Por esta causa, el en sí serpea, según dijimos, a todo lo largo del análisis de la presencia. ${ }^{62}$

\section{c) Aquí y ahora}

Como factor inexcusable de la presencia, se señalan el lugar y el tiempo del sujeto. En realidad, el aquí y el ahora establecen la coincidencia entre el sujeto y el objeto, constitutiva de la presencia. Hablar, por tanto, del lugar y del tiempo del sujeto resulta una expresión incompleta, ya que en el aquí y el ahora deben coincidir tanto el sujeto como el objeto. Lo que sigue nos permitirá comprender los motivos por los que se habla del sujeto antes que del objeto.

Aquí y ahora son limitantes del sujeto y del objeto. "La mesa encargada aún no está en lugar alguno", "la mesa destruida ya no está en lugar alguno" ( $H$ 346), son juicios que equivalen a decir que tal objeto no existe aún o no existe ya. De esta manera, el espacio del aquí y el tiempo del ahora condicionan el hecho de la presencia. Por ello, la proposición "esta mesa no ha estado, ni está, ni estará en lugar alguno" ( $H$ 346) es un pensamiento contradictorio, pues el demostrativo esta de la mesa nos indica que ella es un percepto presente, y por tanto existente, pero al excluirse de ella todo aquí y todo ahora le estamos negando la existencia.

La existencia como presencia constriñe las posibilidades de la realidad al espacio y al tiempo, esto es, a las coordenadas kantianas de las formas a priori de la sensibilidad, que lo son de toda experiencia posible. De ahí la importancia de haberse incluido el nusquam latino dentro de las formas de negación, ya que nusquam, al significar en ningún lugar y en ningún tiempo elimina del objeto connotado por este adverbio la posibilidad de una presencia: será un equivalente del no ser o de la nada. Quede ahora en suspenso el análisis de un posible objeto concebido como posible en todo lugar y en todo tiempo.

62 La expresión en sí o en st mismo aparece en Del hombre, a lo largo del mencionado análisis, en las siguientes páginas al menos: 331 (1), 333 (1), 335 (4), 336 (3), 341 y 354. 
d) El contexto

El cuarto elemento componente de la presencia es el hecho de que lo presente se encuentra entre los demás presentes integrantes del lugar. No se subraya cuál es el motivo por el que, de varios objetos, todos presentes en un lugar, uno de ellos es el que se considera protagónicamente presente, en tanto que los demás forman sólo su contexto o, como diría Ortega, su entorno.

No hay duda de que se tiene en cuenta la atención del sujeto presencial ( $H 366$ y 367), que Gaos denomina "atención percipiente". Pero no se otorga especial relevancia a ella, siendo así que en Sartre el hecho de atender a un objeto es factor principal en su fenomenología de la nada, no tanto para considerarlo presente, sino, al revés, para considerarlo ausente, lo cual constituiría uno de los fenómenos psíquicos de nuestro contacto con el noser. Tal ocurre en el famoso pasaje de "Pedro no está aqui"; pues en Sartre "el no-ser no viene a las cosas por el juicio de negación: al contrario, el juicio de negación está condicionado y sostenido por el no ser". ${ }^{63}$

Nada de ello encontramos en Gaos. La presencia de la mesa - de la que los demás objetos del aula son su entorno- es algo meramente inocuo, el objeto necesario para hacer un ejercicio fenomenológico, y no una realidad que suscite previamente el interés de quien hace ese ejercicio. La presencia del objeto - y, en su momento, su ausencia - no deriva de un hecho psíquico sino de un objeto elegido como ejemplo. La prueba es que la falta de atención puede generar, al contrario, la ausencia de la mesa ( $H 366$ y 367), mientras que en el caso de Sartre la ausencia del objeto se hacía consciente por la atención que le estábamos prestando. Nuevamente vemos en el autor hispano-mexicano un deseo de objetividad para no hacer el falso paso de sus realidades psíquicas subjetivas a las físicas objetivas. ${ }^{64}$

\section{e) El sujeto presencial}

Por último, la presencia se da no ya entre sino para un sujeto, que es el otro relato de la situación de la presencia. El objeto presente puede ser cualquiera capaz de constituirse en percepto. Todos los objetos o sustancias materiales son susceptibles de estar presentes. En cambio, el sujeto ante o para el cual están presentes es un sujeto muy cualificado: no le basta -casi diríamos que le sobra - ser material, sino, además, consciente. Los meros

63 Jean-Paul Sartre, El ser y la nada, pp. 44-51.

64 Gaos no se exime de considerar el interés por un objeto (o persona) como origen de la advertencia de su presencia o ausencia: "he notado la ausencia de la persona aludida porque me interesa su presencia" ( $F$ 388). Lo que queremos decir es que no le da a ese interés relevancia especial en el análisis fenomenológico de la presencia. 
objetos no están presentes entre sí. Sólo pueden estar presentes para o ante un sujeto consciente de los objetos y de sí mismo. Ésta es la razón por la cual Gaos privilegia al sujeto sobre el objeto en toda situación de presencia: no sólo le está presente lo presente, sino que está presente para sí mismo también. "Yo estoy presente para o a mí mismo, yo me estoy presente a mí mismo como fenómeno de conciencia..." ( $H$ 333).

Lo cual nos indica que aún debe analizarse si la existencia - no sólo la presencia- exige un sujeto presencial, y si este sujeto ha de ser trascendental o empírico.

\section{Aparición y desaparición}

La presencia de los objetos se halla en indisoluble vínculo con la aparición previa y desaparición posterior de ellos. Y procede "examinar cómo la aparición y desaparición condicionan el pensar el concepto 'no presente' o "inexistente'" ( $H$ 360). Este examen es uno de los pasos cruciales del análisis del no existente que estamos llevando a cabo.

Porque, identificada la existencia con la presencia, la aparición viene a asimilarse con la creación del objeto que aparece en mi presencia, y la desaparición del objeto que desaparece de mi presencia se asemejará a la aniquilación ( $H$ 350). Como los objetos presentes están "apareciendo aquí hace un instante" y "desapareciendo de aquí dentro de un instante" ( $H 360)$, parece sugerir que se están creando y aniquilando de manera permanentemente sucesiva.

El fenómeno de que la mesa entre y salga del aula es concebido por nosotros como aparición y desaparición; mientras que en el de su fabricación y posterior destrucción ya no hay mero desplazamiento sino que aquellos dos extremos (el taller donde se hace y la trastera en donde se deshace), son considerados como creación o aniquilación de la mesa, respectivamente (H 362-363).

Así, la existencia como mera presencia fenoménica entra en una tesitura de crisis.

\section{Negación o desplazamiento}

El concepto de desplazamiento tiene gran importancia en Gaos para la explicación fenoménica de la presencia. Pero no es suficiente, sea si se considera el desplazamiento del objeto, ${ }^{65}$ incluso concibiendo la fabricación y la construcción como desplazamiento de sus partes; ${ }^{66}$ sea si se considera

$65 H 360-363$ y 371 .

66 H 364. 
el desplazamiento del sujeto y de la atención de éste respecto del objeto presente. ${ }^{67}$

A la inteligencia no le basta explicar la aparición y desaparición como mero desplazamiento, si es que se vinculan intrínsecamente la presencia y la existencia. ${ }^{68}$

Hay un tipo muy peculiar de desplazamiento (o desaparición) que tiene gran importancia no sólo en el suceso de nuestra vida personal, sino dentro del pensamiento existencialista: el desplazamiento o desaparición del sujeto debido a su propia muerte. Karl Jaspers, en su Filosofía, considera precisamente la muerte como un irse definitivo, un dejar a los otros sujetos y objetos, entre los que se encontraba el sujeto que se muere. ${ }^{69}$ También la muerte es para Heidegger uno de los orígenes de la angustia en donde "se descubre la nada".70

Pero la muerte, para Gaos, al menos en este análisis, no es sino un caso más de ausencia o desaparición, como el nacimiento lo es de aparición o presencia, y un caso que no reviste especial relevancia, ya que no se está hablando de la muerte personal, sino de la eventualmente representada por un sujeto respecto de sí, por analogía con lo que acaece a otros sujetos ( $H 359,367,368$ ).

He aquí, por lo tanto, la opción ante la que Gaos ahora se encuentra: $S i$ concibe la aparición o desaparición como mero desplazamiento, o como creación o aniquilación. Tiene la seguridad de que alguien le estará objetando mentalmente: "es absurdo concebir que la aparición y desaparición (de una mesa) en plena clase sean una creación y aniquilación de ella" $(H 363$ y 364). 'Le respondo: 'absurdo' puede querer decir dos cosas: absolutamente

67 H 366, 367 y 369.

68 Sartre también se ha percatado de la importancia de la aparición del ser: "el ser primero que encontramos en nuestras investigaciones ontológicas es el ser de la aparición" (El ser y la nada, pp. 15-16), pero tiene que rendirse al hecho de que "el ser del fenómeno no puede reducirse al fenómeno de ser. El fenómeno de ser exige un fundamento transfenoménico" (ibid.). En efecto, no hay sólo aparición: también hay distancia, una distancia que ha de ser franqueada, es decir, negada: "por medio de un ejemplo - la noción de distancia- podemos comprobar que la negación se halla presente en la realidad" (El ser y la nada, pp. 57-62). Aquí cabe la cuestión que Gaos nos está planteando: esta negación, este desplazarse recorriendo la distancia mediante, ies la creación del ser distante? Ya hemos visto también cómo en Bergson el desplazamiento, o más exactamente el reemplazo de una cosa por otra, le sirve como ejemplo para patentizar la improcedencia de la idea del no ser. Pero ahora vemos, con Gaos y Sartre, que el desplazamiento del objeto, del sujeto o de la atención de éste sobre aquél, nos impide concebir el no-ser como mero desplazamiento, o, en el mejor caso, nos impide una plena identificación de ambos.

69 Cfr. Carlos Llano, "Una aproximación filosófica al problema de la muerte", Istmo, no. 129, México, julio-agosto, 1980, p. 29.

70 Heidegger, ¿Qué es la metafísica?, p. 20. 
imposible o simplemente no razonable. Absolutamente imposible niego que sea concebir la fabricación y la destrucción como desplazamientos" (ibid.). "Y por la misma razón niego que sea absolutamente imposible concebir la aparición de los mozos con la mesa por esa puerta como una creación, y la desaparición de ellos con ella por esa puerta otra vez como una aniquilación. Al desaparecer por ella, mesa y mozos no pasarían al corredor, sino que caerían, como por escotillón, en la nada; y al aparecer por la puerta, no habrían venido del corredor, sino que se habrían creado en la puerta misma" ( $H$ 364).

"Pero les concedo que el concebir [...] las apariciones y desapariciones [...] como creaciones y aniquilaciones [...] sea menos razonable. .." (Ibid.).

Lo que Gaos deja entrever, aunque no lo manifiesta, es que en esta opción (por absurda que pueda parecer una de las alternativas) estamos optando, positiva o negativamente, por el método fenomenológico entero. Si la existencia se identifica con la presencia, no sólo es posible pensar la aparición como creación y la desaparición como aniquilación, sino que resulta imposible pensarlas de otra manera.

Ante esta imposibilidad, Gaos confiesa "una resistencia a concebir todas las apariciones y desapariciones de sustancias, que esto son las mesas, como creaciones o aniquilaciones" ( $H$ 372).

Si se cede a esta resistencia, si admitimos una aparición no creadora y una desaparición no aniquiladora, desembocamos, de la mano de la fenomenología de la negación, a "pensar en el concepto 'existencia metafísica' o 'existente metafísico" ( $H$ 372).

\section{Objetos no presentes para ningún sujeto}

En efecto, si consideramos que la mesa no presente ha sido meramente desplazada, estamos admitiendo que la mesa puede existir en el aula de al lado aunque no esté presente ningún sujeto. Y ni siquiera sería necesario su traslado a otra aula, ya que basta la ausencia de atención percipiente, "el no atender y no percibir equivale perfectamente a la 'no presencia' en el lugar" ( $H$ 367). De modo que "si he concebido la previa 'existencia' de ella (de la mesa) en el aula [...] vacía" ( $H$ 368), "esta 'existencia' plantea un problema del alcance que veremos..." (Ibid.).

¿Puedo llegar a concebir "como 'existente' en el riguroso sentido correlativo de la 'no presencia a sujeto alguno'"? Con todo lo dicho antes sobre la estructura de là presencia, icabe una presencia sin sujeto?

A partir de aquí, parece inevitable desembocar en una presencia representada "no posterior ni anterior a no presencia en lugar alguno" ( $H$ 371), esto es, puede llegar a concebirse una "existencia eterna" con "no presencia de sujeto gramatical alguno" (ibid.). 
Pero si así la concebimos, hemos cambiado el concepto de existencia; una existencia sin presencia alguna no sería algo contradictorio sólo si entendemos existencia en dos sentidos diferentes: "como presencia o existencia fenoménica y como existencia metafísica" ( $H$ 372).

Por lo pronto, ambas opciones, por opuestas que parezcan, coinciden en ser realistas, porque la presencia sin sujeto entraría en conflicto con el idealismo trascendental, que lo consideraría contradictorio ( $H 340)$, y frente al idealismo empírico o subjetivo, pues éste exige que el sujeto presente esté en el sujeto y no ante el sujeto. Pero se encontraría igualmente en contradicción con la misma fenomenología de la presencia, representada aquí por el propio Gaos, pues el fenómeno de la presencia requiere de un sujeto para, a o ante quien presentarse.

No estamos tampoco tratando de un solipsismo estúpido, ya que cuando digo que la existencia del fenómeno requiere su presencia para mí no estoy refiriéndome como sujeto individual: puedo pensar la existencia como presencia "para o a otro sujeto, si distinto de mí, igual a mí en cuanto sujeto presencial" ( $H$ 341).

La aparición no pensada como creación y la desaparición no pensada como aniquilación, constituye una coyuntura optativa, ya que ambas (aparición y desaparición por un lado, o creación o aniquilación por el otro) son posibles, y algunas de ellas incluso impuestas por el sentido común, o por importantes tendencias filosóficas (el idealismo trascendental o la propia fenomenología). Por eso es una opción radical filosófica la de la admisión o rechazo de la metafísica a partir de una fenomenología de la presencia y de la no presencia (aparición y desaparición).

\section{Existencia fenoménica y existencia metafísica}

Cuando nos planteamos la alternativa de una existencia no presente (que sería el umbral de la existencia metafísica) no nos estamos refiriendo a una presencia presente, ya que lo presente de ésta no puede negarse sin contradicción, sino a una presencia representada: "ninguna de las presencias negadas sin contradicción es una presencia presente. Y se comprende: la presencia presente es cierta; no puede negarse sin contradicción y falsedad" ( $H$ 347). Pero cuando concebimos "una existencia no presente para ningún sujeto" tampoco nos estamos refiriendo a "presencias representadas como presentes, es decir, afirmadas en el tiempo pasado o futuro o/y en el lugar distinto de la presencia presente" (ibid.). Estas presencias presentes negadas en el concepto de "presente para ningún sujeto", estas presencias negadas sin contradicción son "presencias puramente concebidas para negarlas" ( $H$ 349). 
En el análisis que se hizo del no existencial pudimos concluir que todo no es un no existencial elíptico. Por esto, si la existencia coincide con la presencia para un sujeto, todo no equivale, en rigurosa lógica, a un no de la presencia. "Si 'no' comprende analíticamente 'presencia' o 'existencia' no podría comprender igualmente notas diferentes de 'presencia' y 'existencia', hasta ser excluyentes de ésta, haciendo de él un concepto contradictorio" ( $H$ 355). Esta resuelta y aguda observación de José Gaos lo empuja hacia la concepción de la existencia metafísica. Su conclusión es también rigurosamente lógica:

"Luego, para que pueda pensarse sin contradicción el concepto 'no' con [...] el concepto 'presencia' que comprende, es forzoso que no haya sólo presencia presente y presencia representada, es forzoso que haya otra cosa." "En otros términos: la negación verbal, el concepto 'no', requieren por condición de posibilidad algo más, o menos, que la presencia presente y representada. ¿Qué?" (H 355). ${ }^{71}$ Para que la negación de la presencia presente no fuera contradictoria se requirió la posibilidad de una presencia distinta, una presencia representada. Pero para negar la presencia representada, "puramente concebida como negada", para poder pensar una existencia ante ningún sujeto, "se requiere algo distinto de la presencia" ( $H 356$ ).

Nos hemos encontrado de bruces con la existencia no como presente para un sujeto, sino con la existencia como el en sí de la cosa: la existencia metafísica: "Nos ha traído de la negación de la presencia o existencia de los fenómenos al pensar el concepto 'existencia metafísica' o 'existente metafísico'" ( $H$ 373). De suerte que concebir la existencia como en sí es la peculiar o paradójica relación con algo, relación que consiste precisamente en la falta de relación con él ( $c f r . H$ 393).

Se concibe entonces la existencia como un factor de la cosa, no relacionalmente tomada respecto de un sujeto, sino como en sí, de tal modo que la presencia o ausencia del sujeto que lo piense es irrelevante. De manera que, ahora, la opción entre existencia fenoménica (existencia como presencia para un sujeto) y existencia metafísica (existencia como el en si de la cosa) adquiere condiciones de apremio. En efecto, la existencia metafísica no sólo tiene en su favor la resistencia que ofrece el hombre común para admitir la aparición y desaparición como creación o aniquilación, sino también, ahora, la necesidad de que el fenómeno incontestable de la expresión verbal, el "no", no se convierta en contradictorio.

71 [Las cursivas son mías.] Recordemos que Sartre, en un planteamiento por completo diverso, concluye también que para explicar la aparición del fenómeno (y puede suponerse que de igual manera la desaparición) se requiere un fundamento transfenoménico ( $c f r . ~ E l ~ s e r$ y la nada, pp. 15-16). 
Esto constituye una de las conclusiones en que termina el tratado De la filosofía: "la cuestión de por qué concebimos existentes metafísicos resultó reducida a la cuestión que ya nos había planteado el 'no': la razón de ser de éste" ( $F$ 379).

No podemos dejar de subrayar el vuelco dado por Gaos a las filosofías existencialistas, e incluso a las conclusiones fenomenológicas. Para Sartre y Heidegger, el no-ser, la negación, es origen o consecuencia de la nada (de la muerte, de la ausencia, de la no allendidad).$^{72}$ En Gaos, el fenómeno verbal del "no" exige como salvamento la concepción de la existencia metafísica, y por lo tanto independiente de todo sujeto. Igualmente, una fenomenología rigurosa llegaría a la conclusión de que sólo puede aceptarse lo dado en el fenómeno; en cambio, la desarrollada por Gaos -que nada pide en rigor a la de ningún otro- aterriza en la necesidad de trascender el fenómeno llegando a la existencia metafísica. ${ }^{73}$

\section{El infinito en la existencia}

Al liberarse la existencia del sujeto presencial, se ha desprendido también de las otras dos condiciones de posibilidad que lo acompañan, y que embonan, por decirlo así, el sujeto presencial con el objeto presente: el aquí y el ahora. Concebida la existencia como lo que existe en sí, con independencia de un sujeto que lo piense y ante el que esté presente, la realidad existente deja de constreñirse al espacio y al tiempo, que eran -recuérdese- las condiciones peculiares del sujeto (y del objeto en cuanto correlato de éste).

Esta liberación espacio-temporal nos capacita para concebir la realidad con la posibilidad de ser eterna (incluso con "presencia representada 'eterna' a una serie 'eterna' de sujetos o a un sujeto 'eterno'" (H 365). Y concebirla igualmente "como espacialmente infinita" ( $H 365)$.

"Que no tengamos razón alguna para concebirla así no hace lógicamente imposible concebirla así, y no es sin más seguro que no tuviéramos, si no 'razón' alguna, algún 'motivo' para concebirla así" ( $H$ 365); $7^{74}$ es decir, temporalmente eterna y espacialmente infinita. ${ }^{75}$

72 Es verdad que en Martín Heidegger hay vislumbres de trascendencia ("en la clara noche de la nada de la angustia despunta la originaria revelación del ser como tal: que es ser, esto es, y no nada" - ¿Qué es la metafísica?, p. 23-), pero finalmente desemboca en el derrotismo del ser para la muerte.

73 En esto coincidiría Gaos, desdé una perspectiva radicalmente diversa, con otro coetáneo y próximo suyo, Octavio Paz: "somos 'el fundamento de una negatividad', pero también la trascendencia de esta negatividad" (El arco y la lira, p. 130).

74 [Las cursivas son mías.]

75 Gaos pone especial cuidado en manifestarnos con sus expresiones que está hablando ahora de existencia metafísica infinita sólo concebida, y por lo tanto no también existente. 
La negación se erige, pues, como "órgano de infinitación" (F 392): "es la creación del hombre, es lo que el hombre introduce en la naturaleza..." (ibid.). Hemos de subrayar de nueva cuenta el contraste: la negación no introduce la nada, o el no-ser, sino la infinitud: el pensamiento humano es discursivo y categorial, pero "entre las categorías resultan ser cardinales y radicales y supremas las negativas, y singularmente la infinitud divina - lo que da dos sentidos más de la razón humana: facultad de negar con conceptos y de concebir lo infinito, singularmente a Dios. Dar razón de estos conceptos es, pues, dar razón de la razón misma..." ( F 385). Ello implica, a la par, la necesidad de dar razón de lo existente por pensarlo inexistente (F 348).

Éste es uno de los puntos en que concluye De la filosofía: "Los conceptos 'no' e 'inexistencia' revelaron ser sinónimos. Los conceptos 'finito' e 'infinito' revelaron no sólo estar correlacionados por el 'no' o la 'inexistencia' como todos los conceptos contradictorios, sino entrañar un 'no' o una 'inexistencia' en forma de una negación de la negación" ( $F$ 385). Usando otra expresión audaz, dirá que hay un no "ingerido entre ellos" ( $F$ 376). "La inexistencia reveló una 'ausencia total'. La 'infinitud divina', en cuanto existencial [ya no en cuanto concepto], equivale a la concepción de una 'presencia sin ausencia alguna" (ibid.).

\section{Finitud, otredad y presencia}

Dice Leo Elders que "debemos dividir el no-ser en ser como potencialidad, ser como otredad y como negación. El hombre solamente hace existir a la última. .."76 En las cosas reales —añade_- "existe otredad, ausencia y limitación, pero existe negación [sólo] porque ésta es función del juicio humano".77

Para José Gaos la negación "es la creación del hombre, lo que el hombre introduce en la naturaleza" ( $F$ 392). Pero resulta explicable preguntarnos el motivo, si no la razón, por la que finca su estudio de la negación humana en el fenómeno de la presencia (o, más bien, en el de la ausencia), y no en el de la potencialidad (limitación y contingencia) o en el de la otredad, que son dos posibilidades adicionales en que indudablemente se da pie para que el hombre proceda a ese acto del todo peculiar y siniestro de la negación.

El mismo cuidado - nótese- ha puesto cuando se refiere a la existencia metafísica (no ya infinita, sino meramente metafísica). "La no presencia de las mesas [...] es una existencia tan sólo concebida, como antes subrayé con la voz un par de veces, y concebida metafísicamente..." (H 339).

76 Leo Elders, Jean-Paul Sartre..., p. 95.

77 Ibid., p. 80. 
El pensamiento de Gaos entraña una especial dificultad para considerar como punto de partida de la negación lo que hay en la realidad de potencial, finito o contingente. En todo caso, y con frecuentes incertidumbres, el o lo infinito es punto de llegada a partir de la negación o el no, pero ello no implica que el punto de partida deba ser lo finito, aunque la historia tradicional haya tenido acceso a la existencia de la infinitud divina - con su necesidad y actualidad correspondiente - partiendo de la existencia de lo potencial, finito y contingente. Tales características encontradas en toda realidad intramundana incapacitan a ésta para dar razón de sí, y exigen por ende una existencia actual, infinita y necesaria.

Gaos manifiesta dudas acerca de que lo finito sea realmente un concepto negativo. Según acabamos de ver ( $F 385$ ), el concepto de infinitud implicaría una doble negación. Sin embargo, su pensamiento entero se muestra dubitativo en ese punto. Él mismo confiesa que, en una etapa de su vida intelectual, pensó que la contingencia del ser era fenoménica, para considerar después que se trataba de una intrusión metafísica subrepticia en el fenómeno.

Por otra parte, la filosofía de Gaos admite la posibilidad de concebir un mismo ente como existente y como inexistente (aunque no obviamente de un modo simultáneo) (cfr. $F$ 355). Esta posibilidad es lo que distingue al ente y a la existencia entre sí (cfr. ibid.). Pero que un ente no sea el ser o la existencia, sino que sólo pueda tenerla o no tenerla (existir y ser o no existir y no ser) es precisamente lo que define a un ente potencial, finito y contingente. Sin embargo, no sabemos que Gaos haya pasado de la posibilidad de concebir un ente como distinto de su existencia (esto es, la posibilidad de la contingencia), a la afirmación de la realidad de la contingencia.

No puede ignorarse que la consideración del mundo como contingente implicaría una virtual aceptación de la prueba cosmológica de la existencia de Dios (tercera vía tomista). La posición de Gaos aquí - y tal vez solamente en esto- es semejante a la de Sartre, para quien, a lo sumo, la contingencia de que se habla no es una contingencia real o fenoménica, sino una contingencia abstracta, es decir, mi idea de contingencia. ${ }^{78}$

Esta manera de considerar que lo potencial, finito y contingente resulta fenomenológicamente problemático $-\mathrm{y}$ poco propicio por tanto para ser punto de partida en el análisis del acto de la negación o el "no"- se hace manifiesto en el ya citado estudio "El significado del Lambda", aunque siempre en forma no definitiva. Congruente con su idea de que las grandes opciones filosóficas son intervenidas por mociones y emociones volitivas o

78 Cfr. Jean-Paul Sartre, Lexistentialisme est un humanisme, p. 93. El ser y la nada, pp. 571, 585. Sartre, respecto de la finitud e infinitud, piensa también que ha sido introducida por el pensamiento (L'existentialisme est un humanisme, p. 93 y El ser y la nada, pp. 11 y 14). 
pasionales, Gaos opina que el núcleo del pensamiento aristotélico expuesto en el mencionado libro de su Metafísica resiente esta intrusión no teorética: "El pensamiento dominante, desde la raíz, del discurso mental del texto, es el de la primacía del acto sobre la potencia. Pero la razón aducida como decisiva, la imposibilidad del acto posterior a la potencia (1071b 22-31), no es nada concluyente [...]: la creación no es menos imposible que la aniquilación. Luego no sería del todo infundado suponer que el ni siquiera atisbar esta contrarrazón - si es que no la atisbó Espeusipo- esté motivado por el significado de tales pensamientos, dominados por las ideas del ser y del no-ser, conmovidos por el horror del no-ser y el afán - la filía - no de ser, sencillamente, sino de ser infinitamente, que motivaría la idea de la infinita potencia activa del acto puro (1073a 5-8)."79 Por esto, la finitud y la contingencia no nos ofrecen una base fenomenológica para el estudio del no, ya que "no sería del todo infundado suponer" que estos conceptos hayan sido insertados por las propias emociones subjetivas.

No dudamos de que en esta interpretación de Aristóteles, según la cual se arbitraría el concepto de potencia por motivo del horror a la nada, aparece en Gaos una sombra de Heidegger. ${ }^{80}$ El hombre le da la espalda a la nada, perdiéndose a sí mismo en sus quehaceres "dentro de la evidente superficialidad de la existencia". 81 Pero Aristóteles no termina en la mediocridad gris de la potencia, sino en el acto puro: ésta sería una versión optimista de Gaos, tal como ve la metafísica de Aristóteles, contraria al pesimismo existencialista de Heidegger.

El segundo posible punto de partida para el análisis del "no" es la otredad: el hecho de que lo uno no es lo otro constituye un fenómeno de negatividad tan claro y manifiesto como la presencia y ausencia del sujeto. Lo otro implica el no ser: "lo otro es algo que no es como nosotros, un ser que es también el no ser". 82

Para la filosofía tradicional ha sido un misterio noético el hecho de que la negáción, el "no", origen de la idea del no-ser, o idea de no-ser misma, aparezca inmediatamente en el proceso del pensar humano. ${ }^{83}$ ¿Cuál es la razón por la que la inteligencia niega lo afirmado? Ya hemos visto que, en este punto, hay notables discordancias: en Maritain no hay razón alguna

79 José Gaos, El significado del Lambda, p. 580.

${ }^{80}$ Heidegger, ¿Qué es la metafisica?, p. 23. Hay "un reclamo al ser que [en la nada] desaparece en su totalidad".

81 Ibid., p. 25.

82 Octavio Paz, El arco y la lira, p. 129. También para Martin Heidegger la nada incluye un importante ingrediente de "extrañeza, como lo absolutamente otro" del ser (¿Qué es la metafísica?, p. 23).

83 "Lo primero que cae en el entendimiento es el ser; lo segundo, el no ser" (De potentia, q. 9, a. 7, ad 15). 
para la pregunta; ${ }^{84}$ en Roland Gosselin, un acto de la voluntad. . . ; en Gaos, tanto el odio a una realidad o a la realidad, para negarla, como el horror al no-ser para afirmarla.

Aquino contesta precisamente con la otredad, con el hecho de que un ser es diferente del otro: "Lo primero que concibe el entendimiento es el ente: lo segundo, que este ente no es aquel ente." ${ }^{85}$ Esta comparación nos dice que la negación del ente se identifica con el juicio sobre la alteridad entre dos entes considerados.

Para tratar con rigor la cuestión, debemos determinar cuál es la otredad primaria que se le ofrece al entendimiento. Ni Gaos ni Aquino han contestado al preciso punto de la pregunta. Gaos dice que el no ser aparece con la desaparición o ausencia, o la negación de la presencia, pero ¿qué ausencia o qué presencia? Tomás de Aquino afirma que aparece con la otredad de un ser respecto del otro, pero ¿quién es el otro?

Nosotros nos atrevemos a afirmar que en todo juicio intelectual, aun en el más simple, se encuentra ya incluida una primera otredad. Como antes se dijo, en toda proposición subyace elíptico el yo afirmo de ésta, de manera que se da de forma indefectible la alteridad primaria: el sujeto que afirma es consciente de su diversidad respecto del objeto afirmado. Esta afirmación no es algo arrojado al pensamiento sin origen, o por un yo trascendental y anónimo: hay siempre un sujeto individual afirmante.

Pues bien, hemos de señalar que en José Gaos la otredad es punto de partida para el análisis de la negación, al menos con tanta fuerza como la presencia y ausencia. La estructura de la presencia nos reveló la dualidad sujeto-objeto, como factor imprescindible de ella. El objeto no puede con propiedad estar presente ante otro objeto, sino ante o para un sujeto consciente de sí mismo, y consciente, por ende, de su alteridad respecto del objeto que le es presente. Y no podría hacerse tal distinción si no es con base en el pensamiento de que el uno - sujeto- no es el otro -objetoya que "no podemos distinguir dos seres distintos sin concebir que uno no es el otro". 86

Pero, además, observamos que todo el análisis fenomenológico del "no" se encuentra en Gaos cruzado por la categoría intelectual de la otredad.

Primero, en la negación del ser como cópula. Al decirse que "esta hoja no es amarilla", estamos señalando que este ser —la hoja - no es este otro

84 Jaques Maritain, De Bergson a Santo Tomás de Aquino, Buenos Aires, 1946, p. 28: "Basta la actividad propia de la inteligencia para formar tal idea" (la del no ser). En esto coincidiría con Zigliara, para quien el ser se nos presenta ya como opuesto a la nada (Zigliara, Della luce intelectuale e del ontologismo, Roma, 1874).

85 Tomás de Aquino, Summa theologiae, I, q. 2, a. 2 ad 4. Cfr. n. 83.

86 Jaime Balmes, Filosofía fundamental, t. II, pp. 125 y ss. 
ser - lo amarillo. La distinción es doble: se distingue la hoja del amarillo (de lo contrario el juicio afirmativo no sería inocentemente copulativo sino tautológico); y, además, se niega ese modo de la hoja (no es amarilla). No se dice que este ente no es este otro ente, pero sí que este ente no es de este modo. Ambas negaciones, precisamente porque el no ser no es denotante de ningún objeto, sino sólo connotante del ser, siguen la suerte de éste, y resulta que el concepto "no-ser" sería análogo si el concepto de "ser" también lo fuera. ${ }^{87}$ La diferencia entre la sustancia (hoja) y el accidente o modo (amarilla), constituye una verdadera y propia otredad, aunque analógicamente distinta de la que se da entre una sustancia y otra sustancia.

Segundo, en el análisis que se hizo de la negación del ser como existencia. Aquí la presencia y no-presencia (la aparición y desaparición) se encuentra cruzada no sólo por la distinción - y contrariedad- natural entre lo uno y lo otro, sino porque el fenómeno de la aparición y desaparición no puede darse sin las consideraciones expresas de la otredad, como queda patente en el atento estudio del texto relativo de Gaos: la aparición de la mesa significa su venida de otro lugar; su desplazamiento por otra mesa; su presencia en otra aula, para otro sujeto, en otro tiempo, etcétera. ${ }^{\mathbf{8 8}}$

La óptica adoptada por Gaos para estudiar el fenómeno del no, resultaba poco propicia para servirse de lo que hemos denominado otredad primera: la alteridad entre el sujeto afirmante y el objeto afirmado.

Yendo, en efecto, en busca del no radical, se vio precisado, según vimos, a volcarse sobre el no en posición directa, esto es, sobre el "no" que connota como no un concepto denotante de un objeto: esta hoja no es amarilla, en donde el "no" recae sobre la realidad objetiva amarilla, negándola. Es el maximum de negación posible.

Al volcarse sobre el "no" en posición directa, se ve obligado a marginar el juicio en posición refleja: niego que la hoja es amarilla. Aquí la negación o el "no", se refiere al acto noético de negar, y no al objeto real (amarillo) negado. La negación noética, precisamente por noética, tiene menos fuerza

87 Si el concepto de ser es análogo, como postula Aristóteles, el de no-ser también lo será, porque no representa más que la negación del ser (cfr. Raeymacker, Metaphysica generalis, Lovaina, 1935, p. 41). En el caso de Gaos esta misma conclusión se obtendría del hecho de que el no-ser no denota objeto alguno y sólo connota al objeto.

88 En Del hombre, mientras analiza el fenómeno del "no" como existente o el no verbal, el término otro, aparece en pp. 332, 337, 338 (dos veces: otro lugar, otra mesa), 339 (tres veces: aula de al lado, otro sujeto, otro lugar), 341 (tres veces), 343, 344, 345 (siete veces), 346,348 (tres veces), 349 (5), 349 (3), 351, 352 (6), 353, 358 (3), 359, 360, 361 (2), 362 (5), 363 (4), 364 (6), 366 (2), 368 (3), 369 (4), 370 (6), 372 y prevalece incluso sobre los términos de presencia y ausencia o aparición y desaparición. 
que la negación referida a lo real. Esta posición ratifica el realismo del autor $\multimap$ al menos sus apetencias realistas.

Lo anterior impide metodológicamente a Gaos encontrar en la dualidad sujeto-objeto el fenómeno oportuno para emprender su análisis del no. Aun siendo la primera otredad, no necesariamente tiene que ser la adecuada para llegar a la negación más radical y profunda.

Pues bien: consideramos que es más radical y profundo el estudio en posición directa de la negación directa del objeto, que el estudio en posición refleja del acto noético por el que se lleva a cabo mentalmente la negación directa del objeto. Si para esto último se han tenido que indagar las condiciones y presupuestos noéticos necesarios a fin de proceder a la negación directa, como ha sido el caso, nuestra afirmación se refuerza con ello.

La dualidad sujeto-objeto es parte importante de la estructura de la presencia, hasta el punto de que ésta se define como la presencia de un objeto para o a un sujeto; pero no resulta metodológicamente favorable, por las razones dichas, analizar el fenómeno del no partiendo de esta dualidad del sujeto y del objeto, sino de la que nos ofrece la presencia y ausencia de un objeto ante, o a, o para un sujeto, por los motivos que veremos.

La misma presencia y ausencia (o aparición y desaparición) constituye en sí misma una otredad de tanta o mayor radicalidad que la que nos ofrece el hoc ens non est illud ens, este ser no es aquél, propuesto por Aquino, o el yo sujeto afirmante no soy el objeto afirmado, que nosotros proponemos como otredad primera. En efecto, la presencia y la ausencia, en su ámbito estricto, proporcionan una profunda e inigualable otredad entre el objeto y el no o la nada de ese objeto.

No se trata, es verdad, del no total o la nada total, pero sí de la nada o el no en relación con el objeto cuya presencia fue. En ese aspecto, el no o la nada son totales, porque el fenómeno no se lleva a cabo mediante el desplazamiento de una cosa por otra, como quería Bergson, sino por desplazamiento de un objeto respecto de sí mismo: es el objeto el que desaparece, sin que necesariamente aparezca en su lugar otra cosa, ni necesariamente aparezca la cosa en otro lugar.

La alteridad, división, otredad o grieta advertida en el "este ente no es aquel ente", o la advertida en "el sujeto afirmante no es el objeto afirmado", en medio de la diversidad que implican, no constituyen un "no" fundamental, ya que ambos extremos negados son, y si no lo fueran, no tendrían siquiera la posibilidad de que uno no fuera el otro. Entre la ausencia y la presencia de un objeto, en cambio, no se da -dentro del ámbito mismo del objeto ausente o presente-comunidad entitativa alguna. No se diferencia 
un objeto de otro objeto (o de un sujeto) sino un objeto presente de su propia negación como presente (es decir, ausente).

El señalamiento hecho por Gaos de que el "no" no denota objeto alguno deja ver patentemente el nivel radical de la otredad que en ese "no" de la ausencia se nos esclarece.

No se trata de un "no" completo (que se refiriese a la totalidad de la realidad) pero sí de un completo no (en el que no resta nada de realidad del objeto negado). Sería una nada completa pero singularizada por el objeto negado (que es connotado y no denotado); sería, respecto del objeto ausente o desaparecido, su completa o pura nada, aunque sólo en ese aspecto. Ya dijo Gaos que la nada podría ser determinante de algo, y también por algo determinada. Un triángulo de dos ángulos es nada; y es nada también un cuadrado redondo, pero son dos nadas singulares y mutuamente distintas porque los objetos mentales connotados por el no de la nada son distintos mutuamente. Aquí la nada se singulariza por el objeto negado que connota. Para emplear la expresión del magister Eckhart, aunque con contexto y significado diversos, el no representa la otredad más fundamental, porque nos sugiere el unum purum nihil: pura nada, pero una. 